\title{
Evidence for Widespread Associations between Neotropical Hymenopteran Insects and Actinobacteria
}

\author{
Bernal Matarrita-Carranza',2, Rolando D. Moreira-Soto ${ }^{2,3}$, Catalina Murillo-Cruz², \\ Marielos Mora ${ }^{4}$, Cameron R. Currie ${ }^{5}$ and Adrián A. Pinto-Tomas ${ }^{2,4,6 *}$
}

${ }^{1}$ La Selva Biological Station, Organization for Tropical Studies, Heredia, Costa Rica, ${ }^{2}$ Centro de Investigación en Estructuras Microscópicas, Universidad de Costa Rica, San José, Costa Rica, ${ }^{3}$ Centro de Investigación en Enfermedades Tropicales, Universidad de Costa Rica, San José, Costa Rica, ${ }^{4}$ Centro de Investigación en Biología Celular y Molecular, Universidad de Costa Rica, San José, Costa Rica, ${ }^{5}$ Department of Bacteriology, University of Wisconsin-Madison, Madison, WI,

United States, ${ }^{6}$ Departamento de Bioquímica, Facultad de Medicina, Universidad de Costa Rica, San José, Costa Rica

OPEN ACCESS

Edited by:

Robert Brucker,

Rowland Institute at Harvard,

United States

Reviewed by:

Amparo Latorre,

Universitat de València, Spain

Regina Lamendella

Juniata College, United States

${ }^{*}$ Correspondence:

Adrián A. Pinto-Tomas

adrian.pinto@ucr.ac.cr

Specialty section:

This article was submitted to

Microbial Symbioses,

a section of the journal

Frontiers in Microbiology

Received: 05 July 2017 Accepted: 29 September 2017 Published: 17 October 2017

Citation:

Matarrita-Carranza B, Moreira-Soto RD, Murillo-Cruz C,

Mora M, Currie CR and

Pinto-Tomas AA (2017) Evidence for Widespread Associations between Neotropical Hymenopteran Insects

and Actinobacteria.

Front. Microbiol. 8:2016.

doi: 10.3389/fmicb.2017.02016
The evolutionary success of hymenopteran insects has been associated with complex physiological and behavioral defense mechanisms against pathogens and parasites. Among these strategies are symbiotic associations between Hymenoptera and antibiotic-producing Actinobacteria, which provide protection to insect hosts. Herein, we examine associations between culturable Actinobacteria and 29 species of tropical hymenopteran insects that span five families, including Apidae (bees), Vespidae (wasps), and Formicidae (ants). In total, 197 Actinobacteria isolates were obtained from 22 of the 29 different insect species sampled. Through 16S rRNA gene sequences of 161 isolates, we show that $91 \%$ of the symbionts correspond to members of the genus Streptomyces with less common isolates belonging to Pseudonocardia and Amycolatopsis. Electron microscopy revealed the presence of filamentous bacteria with Streptomyces morphology in brood chambers of two different species of the eusocial wasps. Four fungal strains in the family Ophiocordycipitacea (Hypocreales) known to be specialized insect parasites were also isolated. Bioassay challenges between the Actinobacteria and their possible targeted pathogenic antagonist (both obtained from the same insect at the genus or species level) provide evidence that different Actinobacteria isolates produced antifungal activity, supporting the hypothesis of a defensive association between the insects and these microbe species. Finally, phylogenetic analysis of $16 \mathrm{~S} r \mathrm{RNA}$ and gyrB demonstrate the presence of five Streptomyces lineages associated with a broad range of insect species. Particularly our Clade I is of much interest as it is composed of one 16S rRNA phylotype repeatedly isolated from different insect groups in our sample. This phylotype corresponds to a previously described lineage of host-associated Streptomyces. These results suggest Streptomyces Clade I is a Hymenoptera host-associated lineage spanning several new insect taxa and ranging from the American temperate to the Neotropical region. Our 
work thus provides important insights into the widespread distribution of Actinobacteria and hymenopteran insects associations, while also pointing at novel resources that could be targeted for the discovery of active natural products with great potential in medical and biotechnological applications.

Keywords: symbiosis, ants, bees, wasps, Streptomyces, Cordyceps, Ophiocordyceps, Hirsutella

\section{INTRODUCTION}

Hymenoptera is the third largest species-rich insect order, containing more than 150000 extant species described to date (Aguiar et al., 2013), only surpassed by Coleoptera and Lepidoptera. All ants, bees, and wasps belong to this order and, together with termites (Blattodea), represent the bestknown groups of insects where eusociality, the highest-level of social organization, is present. Eusociality is characterized by the presence of reproductive division of labor, brood care and overlapping of generation of individuals of the same colony (Wilson, 1971). These complex social systems and their associated adaptations are what have allowed some hymenopteran groups to achieve ecological dominance playing prominent roles in ecosystem function as pollinators (stingless bees and the honey-bee), herbivores (leaf-cutter ants) and predators (e.g., army ants and paper wasps; Hanson and Nishida, 2016). The success of eusocial insects is reflected for example in tropical forests where they can represent more than $50 \%$ of all animal biomass (Hölldobler and Wilson, 2009).

However, social lifestyles also represent an opportunity for pathogens and parasites to exploit means of dispersion between colony members in order to infect healthy individuals. Moreover, environmental conditions such as humidity and stable temperatures inside the nest are factors that predispose these insects to pathogenic infestations (Oi and Pereira, 1993).

As defensive responses against pathogenic microorganisms, many social Hymenoptera have developed collective hygienic strategies and altruistic behaviors in order to evade, control or eliminate parasitic infections (Wilson-Rich et al., 2009). Beneficial microbial associations may augment integral immune defenses and help provide protection against pathogens via microbial competition, by stimulating immune responses, or through secretion of anti-microbial compounds (Berg, 1996; Bot et al., 2002; Dillon and Dillon, 2004; Evans and Lopez, 2004; de Souza et al., 2009; Kaltenpoth and Engl, 2013).

As suggested by Kaltenpoth (2009), the factors that may have predisposed Actinobacteria to engaging in defensive symbiotic associations with insects are their ubiquity in terrestrial environments (Mayfield et al., 1972; van der Meij et al., 2017), the capability to degrade recalcitrant carbon and nitrogen sources (e.g., lignin, chitin and cellulose; Bhattacharya et al., 2007; Vètrovský et al., 2014), and the potential to produce many bioactive secondary metabolites (Barka et al., 2016). The genus Streptomyces alone produces more than $80 \%$ of all antibiotics with pharmaceutical applications that are used today, either directly as natural products or their semisynthetic derivatives (Bérdy, 2005).

There are two well-studied hymenopteran groups that have established defensive symbiotic associations with Actinobacteria.
The first is comprised of leaf-cutter ants and bacteria in the genus Pseudonocardia. These bacteria are found on the cuticle of the ants and can occur in crypts in their exoskeleton (Currie et al., 2006), and they produce secondary metabolites that can inhibit the growth of parasitic fungi (Escovopsis) that can colonize the ant's fungal cultivar (Currie et al., 1999; Oh et al., 2009; Marsh et al., 2013; Sit et al., 2015). The second group consists of solitary wasps belonging to the genera Philanthus, Trachyphus, and Philanthinus (Kaltenpoth et al., 2005, 2010, 2012) in which females harbor Streptomyces bacteria in specialized gland reservoirs inside the antenna. Before laying their eggs, female wasps secrete their Streptomyces symbiont inside the brood chambers. During larval development, the Streptomyces produce a mixture of at least nine different antimicrobial compounds that will cover immature wasps and protect them from fungal attack during hibernation periods (Kaltenpoth et al., 2005; Kroiss et al., 2010). Actinobacteria have been characterized in several other social Hymenoptera, including within three ant-plant systems (Hanshew et al., 2015) and in bees (Promnuan et al., 2009), suggesting these associations may be more widespread.

Neotropical Hymenoptera are an extremely diverse group of insects (Hanson and Gauld, 1995) with largely unexplored Actinobacteria associations. Here we examine possible associations between Actinobacteria and tropical eusocial and subsocial Hymenoptera, including species of bees, wasps, and ants, in a tropical rain forest at La Selva Biological Station in Costa Rica (Bawa et al., 1994). Culture-dependent targeted isolations for Actinobacteria from 29 hymenopteran species were conducted. Patterns of associations between insect species and Actinobacteria isolates were characterized through 16S rRNA and gyrB DNA sequencing and Bayesian phylogenetic analyses. Moreover, different strains of entomopathogenic fungi known to infect some of the insects under study, including strains in the genus Ophiocordyceps (Hirsutella) were isolated. These fungi are known as highly specialized pathogens capable of manipulating the behavior of their host (de Bekker et al., 2014). Finally, the results from in vitro bioassays show that some strains of Actinobacteria associated with different species of insects were capable of inhibiting the growth of these entomopathogenic fungi.

\section{MATERIALS AND METHODS}

\section{Insect Sampling for Actinobacteria Screening}

Insect colonies were collected at La Selva Biological Station (Organization for Tropical Studies) from 2010 to 2014 (Table 1). This station is located in the province of Heredia, Costa Rica $\left(10^{\circ}\right.$ 
$25^{\prime} 53.14^{\prime \prime} \mathrm{N}, 84^{\circ} 0^{\prime} 10.51^{\prime \prime} \mathrm{W}$ ) and is composed of 1500 hectares of lowland tropical rain forest. A few other samples were collected in Las Brisas Nature Reserve, Limón Province, Costa Rica $\left(10^{\circ}\right.$ $04^{\prime} 09.7^{\prime \prime} \mathrm{N}, 83^{\circ} 37^{\prime} 57.5^{\prime \prime} \mathrm{W}$ ). Samples from each colony were aseptically collected using flame sterilized forceps and placed directly into a capped sterile container for transport to the laboratory. Each colony was divided into different sub-samples for further Actinobacteria isolation. Colony components when present included larvae, adults, nest material and honey or pollen in the case of bees. Our sampling approach encompassed eusocial insects (all ants, paper wasps, and stingless bees) and non-eusocial insects (bees from the tribe Euglossini, and wasps from the family Pompilidae and Crabronidae).

Ten different species of ants representing four sub-families and spanning different lifestyles and habitats were collected. The ant species sampled comprised, Tapinoma ramulorum (Dolichoderinae), Paratrechina caeciliae (Formicinae), and Pheidole fiorii (Myrmicinae), which build carton nests on the leaves of different plants, and Pheidole bicornis (Myrmicinae) that obligatorily lives in cavities of the petioles and stems shrubs from the genus Piper. Four different ant species in the genus Odontomachus (Ponerinae) which live under rocks or trunks, were also sampled. Finally, Paraponera clavata (Paraponerinae), an omnivorous large ant that constructs nests in the soil next to the base of trees and is a member of a recent paraphyletic ancestor group to the formicoid ants lineage was also studied (Ward, 2014).

In the case of eusocial wasps, Actinobacteria associations with colonies of Agelaia cajennensis, Polybia plebeja, Polybia occidentalis, and Metapolybia docilis were studied. Subsocial wasps in the families Pompilidae and Crabronidae were also sampled (Table 1). The Crabronidae family is related to the Apidae lineage (Debevec et al., 2012) and known as mud daubers together with Sphecidae.

From the eusocial stingless bees, Tetragonisca angustula and Trigona sp. 1 were investigated. Adults, larvae, comb,

TABLE 1 | Insect species and colony components sampled and Actinobacteria isolates obtained.

\begin{tabular}{|c|c|c|c|c|c|c|c|}
\hline \multirow[b]{2}{*}{ Insect family } & \multirow[b]{2}{*}{ Species } & \multirow[b]{2}{*}{ Colonies sampled } & \multicolumn{5}{|c|}{ Number of isolates obtained from: } \\
\hline & & & Adult & Larvae & Nest & Others & Total \\
\hline & Euglossa hansoni ${ }^{\ddagger}$ & 1 & 0 & - & - & - & 0 \\
\hline & Euglossa heterosticta ${ }^{\ddagger}$ & 6 & 2 & - & - & - & 2 \\
\hline & Euglossa ignita ${ }^{\ddagger}$ & 1 & 0 & - & - & - & 0 \\
\hline & Eulaema speciosa ${ }^{\ddagger}$ & 2 & 0 & 0 & 0 & 0 & 0 \\
\hline & Tetragonisca angustula ${ }^{\dagger}$ & 16 & 7 & 2 & 0 & $10^{*}$ & 19 \\
\hline & Trigona sp. $1^{\dagger}$ & 4 & 0 & - & 0 & - & 0 \\
\hline \multirow[t]{7}{*}{ Formicidae $^{\dagger}$} & Crematogaster longispina & 10 & 5 & 4 & 1 & - & 10 \\
\hline & Odontomachus bauri & 3 & 0 & 1 & 0 & - & 1 \\
\hline & Paraponera clavata & 16 & 18 & - & - & - & 18 \\
\hline & Paratrechina caeciliae & 10 & 7 & 4 & 1 & - & 12 \\
\hline & Pheidole bicornis & 13 & 0 & 2 & 5 & - & 7 \\
\hline & Pheidole fiorii & 8 & 4 & 1 & 0 & - & 5 \\
\hline & Tapinoma ramulorum inrectum & 8 & 4 & 1 & 3 & - & 8 \\
\hline Pompilidae ${ }^{\ddagger}$ & Pompilidae sp. A & 3 & 1 & 2 & 0 & - & 3 \\
\hline \multirow[t]{2}{*}{ Crabronidae ${ }^{\ddagger}$} & Trypoxylon sp. A & 4 & 3 & 8 & 4 & - & 15 \\
\hline & Trypoxylon sp. B & 1 & 1 & 1 & 0 & - & 2 \\
\hline \multirow[t]{3}{*}{ Vespidae $^{\dagger}$} & Agelaia cajennensis & 11 & 3 & 16 & 3 & - & 22 \\
\hline & Metapolybia docilis & 10 & 3 & 6 & 15 & - & 24 \\
\hline & Polybia plebeja & 13 & 1 & 6 & 5 & - & 12 \\
\hline
\end{tabular}

${ }^{\dagger}$ Eusocial insects studied (all ants, paper wasps, and stingless bees). ${ }^{\star}$ Non-eusocial insects (mud dauber wasps and Euglossini bees). *Isolates obtained as follows: three from honey, one comb, one pollen, and five propolis. 
honey, and pollen from colonies of T. angustula were collected; antimicrobial activity has been reported for this species' honey (DeMera and Angert, 2004). Adults and beehive entrance material were the only colony components of the Trigona sp. 1 collected.

Five species of the weakly social orchid bees (Cardinal et al., 2011) were studied using essential oils as bait to collect males (Table 1). Finally, adults and larvae specimens from two colonies of the solitary-nesting orchid bee Eulaema speciosa were included in the study.

\section{Actinobacteria Isolation}

A culture-dependent approach for isolating Actinobacteria was performed, using chitin agar as a selective media (Cafaro and Currie, 2005). For small insects (e.g., C. longispina, T. ramulorum, $P$. bicornis, $P$. fiorii, and $P$. caeciliae) five adults, five immature forms (larvae and pupae) and five nest fragments from each colony were placed separately into $0.5 \mathrm{~mL}$ of $0.1 \%$ sterile tween20 PBS buffer solution in an autoclaved $1.5 \mathrm{~mL}$ Eppendorf tube. For medium sized insects (T. angustula, Odontomachus ants, and all wasps), pools of three adult insects or larvae were used. For P. clavata ants, only adult insects were collected for Actinobacteria isolation. Each sample was vortexed for 15-20 s. Tween-20 PBS solution was pipetted off, discarded and replaced with $0.5 \mathrm{~mL}$ of PBS solution. The sample was macerated with a sterile pestle and $0.5 \mathrm{~mL}$ of PBS was added. Then the microcentrifuge tube was vortexed for $15 \mathrm{~s}$. An aliquot of $100 \mu \mathrm{L}$ was plated onto chitin agar plates and incubated at $27^{\circ} \mathrm{C}$ for three to 4 weeks. Isolated Actinobacteria were subcultured onto yeast-malt extract agar (YMEA) with antifungals (nystatin and cycloheximide) for macro and micromorphology examination. A Gram stain screening of the isolates was performed prior to DNA extractions of the most promising isolates. A $20 \%$ glycerol stock of Actinobacteria spores and cells were prepared by freezing a homogenized mixture in liquid nitrogen and storing them in cryovials at $-80^{\circ} \mathrm{C}$.

\section{Entomopathogenic Fungi Sampling and Isolation}

A total of 14 insect cadavers with conspicuous signs of Cordyceps-like fungal infection were collected and brought to the lab for processing. The majority (11) of specimens were collected in the same geographic area where insect colonies for Actinobacteria screening were sampled. Two wasps (Agelaia areata and Polybia sp.) and one Camponotus ant cadavers were collected in a secondary forest in San Carlos, Costa Rica $\left(10^{\circ} 34^{\prime}\right.$ $\left.26.2^{\prime \prime} \mathrm{N}, 84^{\circ} 30^{\prime} 08.2^{\prime \prime} \mathrm{W}\right)$. Insect cadavers corresponding to the same species or genus as one of the Actinobacteria hosts under study were chosen for fungal isolation, further characterization and bioassay analysis.

Ophiocordyceps infected specimens were of much interest as these fungi have been described as being a hymenopteran host specialist having a narrow host range (Boomsma et al., 2014). Specimens were carefully collected, including a portion of the substrate (leaves or twigs) at which they were attached to avoid damaging the specimen. Samples were placed in sterile plastic containers and brought to the laboratory for processing and identification.

Insect cadavers with fruiting bodies developed or with active conidiophores on stromata were attached with double-sided tape to the inner side of a Petri plate lid. Then the lid was placed on a plate containing PDA media for collecting discharged ascospores or conidia (Lacey, 2012). Pieces of stromata or synnemata were also cut with sterile scissors and directly stroked against PDA media with flame-sterilized forceps, in a laminar flow hood. Agar plates were examined under a microscope and pure cultures were obtained after cutting pieces of agar with single ascospores or hyphal tips and transferred into new PDA plates that were later incubated at $27^{\circ} \mathrm{C}$ for 4 weeks. Agar slants with sterile mineral oil and $20 \%$ glycerol stocks were prepared to preserve the isolates.

\section{DNA Extractions and PCR}

From each colony component sampled, unique isolate morphotypes were chosen for DNA extraction and 16S rRNA sequencing. Standard cetyltrimethylammonium bromide (CTAB) DNA extractions were performed for Actinobacteria isolates (Cafaro et al., 2011). PCR amplifications were employed on the genomic DNA using the eubacterial universal primers, 27F and 1492R (Lane, 1991) for 16S rRNA. As 16S rRNA gene sequence analysis cannot distinguish between closely related taxa (Han et al., 2012) the gyrB coding gene for 71 representative Streptomyces isolates from our collection were sequenced, using the primers $g y r B-F 1$ (GAGGTCGTGCTGACCGTGCTGCA) and $g y r B-R 1$ (GTTGATGTGCTGGCCGTCGACGT) (Hatano et al., 2003). The PCR amplification reactions were performed in a Veriti (Applied Biosystems) Thermal cycler. The reaction conditions for $16 \mathrm{~S}$ rRNA gene amplification consisted of 35 cycles at $94^{\circ} \mathrm{C}$ for $1 \mathrm{~min}, 52^{\circ} \mathrm{C}$ for $1 \mathrm{~min}, 72^{\circ} \mathrm{C}$ for $1 \mathrm{~min}$. The amplification of $\mathrm{gyrB}$ consisted of 30 cycles of denaturation at $95^{\circ} \mathrm{C}$ for $1 \mathrm{~min}$, annealing for $0.5 \mathrm{~min}$ at $65^{\circ} \mathrm{C}$, and extension at $72^{\circ} \mathrm{C}$ for $1.5 \mathrm{~min}$. Bacterial $16 \mathrm{~S}$ rRNA and $g y r B$ sequences obtained in this study were deposited in the GenBank database under accession numbers KY067229-KY067322 and KY082974-KY083044, respectively.

In the case of fugal genomic DNA extractions, a simple thermolysis method was applied (Zhang et al., 2010). Mycelium from 3-day cultures from fast growing isolates was used to extract DNA. In the case of Ophiocordyceps isolates PCFB and BA18 fresh stromata tip from old cultures were used. PCR amplification of ITS region was performed with primers ITS4 and ITS5 (White et al., 1990). SSU was amplified using the primers NS1 and NS4 (White et al., 1990). Amplification of the elongation factor $1-\alpha(E F 1-\alpha)$ was performed with the primers $983 \mathrm{~F}$ and $2218 \mathrm{R}$ and cycling conditions used by Rehner and Buckley (2005). ITS amplification cycling conditions were of 35 cycles of $0.5 \mathrm{~min}$ at $95^{\circ} \mathrm{C}, 0.5 \mathrm{~min}$ at $52^{\circ} \mathrm{C}$ and $1.5 \mathrm{~min}$ at $72^{\circ} \mathrm{C}$. SSU amplification was performed with 35 cycles of $94^{\circ} \mathrm{C} 1 \mathrm{~min}, 52^{\circ} \mathrm{C} 0.5 \mathrm{~min}$ and $72^{\circ} \mathrm{C}$ for $1 \mathrm{~min}$. PCR products cleaning and sequencing was performed either at Macrogen or at the Biotechnology Center DNA Sequencing Facility at the University of Wisconsin-Madison. The GenBank accession numbers for the entomopathogenic fungi isolates sequences 
are KY053448-KY053455 (ITS), KY055528-KY055532 (EF1- $\alpha$ ) y KX579044-KX579053 (18S rRNA).

\section{Analysis of Sequences}

Sequences from this study were edited using Geneious version 9.1.2 and high-quality sequences were clustered into operational taxonomic units (OTUs) using mothur (Schloss et al., 2009) with the standard divergence cut-off of $98 \%$ similarity (Schloss and Handelsman, 2004; Hong et al., 2006; Hulcr et al., 2011). Interactions bipartite network analysis were developed using the R package-bipartite software (Dormann et al., 2008).

Sequence alignments were performed using GUIDANCE (Penn et al., 2010) with MAFFT algorithm and 100 bootstrap repeats. Final editing of alignments was done in MEGA v6.0 (Tamura et al., 2013). Analyses for the best model of nucleotide substitution were performed using jModelTest2 version 2.1.6 (Darriba et al., 2012). The chosen model for $16 \mathrm{~S}$ rRNA and $\operatorname{gyrB}$ sequences was GTR (General Time Reverse) and K80 (Kimura two-parameter) for ITS sequences. Phylogenetic analyses were performed through Bayesian inference, using MrBayes 3.2 (Ronquist and Huelsenbeck, 2003). All analyses employed one cold chain and three incrementally heated chains. A temperature parameter set to 0.2 for ribosomal RNA genes and 0.1 for gyrB. Four separate Markov Chain Monte Carlo runs were performed, with 3 million generations each ( 5 million generations for $\operatorname{gyr} B$ ), discarding the initial $25 \%$ generations from each run as burnin and sampling one in every 100 generations to calculate posterior probabilities for each branch. jModelTest and MrBayes analysis were carried out using the Cipress Science Gateway bioinformatics service platform (Miller et al., 2010). Final editing of each phylogenetic tree was done in FigTree v1.4 and Adobe Illustrator CS5.1.

\section{Bioassays}

Duplicate bioassay challenges between Actinobacteria and entomopathogenic fungi were conducted. In each bioassay, both the bacteria and the fungi were isolated from the same insect host at the genus or species level. To obtain spore suspensions, fungal fermentations were done with a modified methodology (Suay et al., 2000). In the case of Ophiocordyceps/Hirsutella isolates, pieces of agar from pure cultures were transferred to $100 \mathrm{~mL}$ sterile Erlenmeyer's flasks containing $20 \mathrm{~mL}$ of Grace Insect cell medium (Gibco) supplemented with $10 \%$ fetal bovine serum (Gibco). The inoculated flasks were shaken at $250 \mathrm{rpm}$ at $25^{\circ} \mathrm{C}$ for 2-3 weeks. Spore suspensions were prepared by filtering the liquid culture through sterile cheesecloth placed in the tip of a sterile pipette while applying pressure with a pipette pump. Isolates classified in the genera Metarhizium, Chlorocillium, and Engyodontium were cultured directly in PDA plates for 3 weeks at $27^{\circ} \mathrm{C}$. Spore suspensions were obtained by scrapping the mycelium directly from the agar media and transferring to $100 \mathrm{ml}$ sterile Erlenmeyer flasks containing $20 \mathrm{~mL}$ of $0.1 \%$ tween-20 solution. Eight sterile crystal balls ( $3 \mathrm{~mm}$ diameter) were added to the flasks and then shaken at $250 \mathrm{rpm}$ for $10 \mathrm{~min}$. The mycelium was filtered through sterile cheesecloth and spore suspension collected in a sterile beaker. Suspension spore concentration was determined with a hemocytometer. Spore viability was assessed by inoculation of $100 \mu \mathrm{l}$ spore suspension $\left(\sim 1 \times 10^{6}\right.$ spore $\mathrm{mL}^{-1}$ ) on a PDA plate and incubation in the dark at $27^{\circ} \mathrm{C}$ and counting germinated spores within $24 \mathrm{~h}$ (Lacey, 2012).

PDA media was prepared and inoculated with the spore suspension to reach a final approximate concentration of $1 \times 10^{4}$ viable spore $\mathrm{mL}^{-1}$. As we determined that temperatures above $40^{\circ} \mathrm{C}$ compromised spore viability of at least one of our fungal strains, the suspension spores were carefully preheated to $38^{\circ} \mathrm{C}$ and inoculated in PDA media at around $38-40^{\circ} \mathrm{C}$. This avoid the formation of lumps when inoculating agar media with lower temperature spore suspension, keeping a homogenous mixture with viable spores. $24 \mathrm{~mL}$ PDA inoculated media was poured in Petri plate $(8.5 \mathrm{~cm}$ in diameter). For each fungal strain, the panel of Actinobacteria isolates that corresponded to the same insect host were cultured in YMEA at $27^{\circ} \mathrm{C}$ for 2 weeks to reach the stationary phase growth. Then YMEA with Actinobacteria lawn growth was cut into $5 \mathrm{~mm}$ diameter disks and carefully transferred to the PDA media inoculated with entomopathogenic fungal spore suspension. Bioassays plates were incubated at $27^{\circ} \mathrm{C}$ for 2-4 weeks and halos of inhibition were measured. Negative controls were run with YMEA agar disks media only.

\section{Scanning Electron Microscopy}

The ultrastructure of adults and nest material for two vespid wasps ( $M$. docilis and P. plebeja) was examined. Two nest samples and adults per colony were fixed with glutaraldehyde and paraformaldehyde and were left at $4^{\circ} \mathrm{C}$ overnight. Samples were post-fixed in $1 \%$ osmium tetroxide for at least $1 \mathrm{~h}$ and dehydrated with ethanol (SEM; 30-100\%) SEM and then dried by sublimation in a freeze dryer (VFD-20, VD Inc.). Due to the fragile nature of these samples, the processing was repeated with a modified Karnovsky and Osmium vapors fixation protocol (Kim, 2008; Alves et al., 2013). In this case, samples were put in a Petri plate containing a moistened cotton ball. In a fume hood, $1 \mathrm{~mL}$ of Karnovsky's solution (Karnovsky, 1965) was placed in a small opened container that was then transferred into the Petri plate containing the sample. The Petri plate was kept closed and the sample was fixed at room temperature for $2 \mathrm{~h}$. For a second fixation step, the container with Karnovsky solution was replaced with another container that contained $1 \mathrm{~mL}$ of $2 \%$ osmium tetraoxide. The Petri plate was covered with aluminum foil inside the fume hood and the sample was fixed for 12-24 h and then dried with silica gel in a hermetic container for $24 \mathrm{~h}$. The samples were then mounted on aluminum stubs, with a double-stick carbon, coated with gold in a sputter Eiko ID 2 and examined under a scanning electron microscope Hitachi S-3700.

\section{RESULTS}

\section{Actinobacteria Isolation and Phylogenetic Analysis}

In our sampling of 178 colonies of tropical hymenopteran insects, 197 isolates of Actinobacteria were obtained. Of the 29 different species of insects sampled, Actinobacteria was obtained from 22 (Table 1). Isolation of Actinobacteria from a particular species 


\section{Insects}

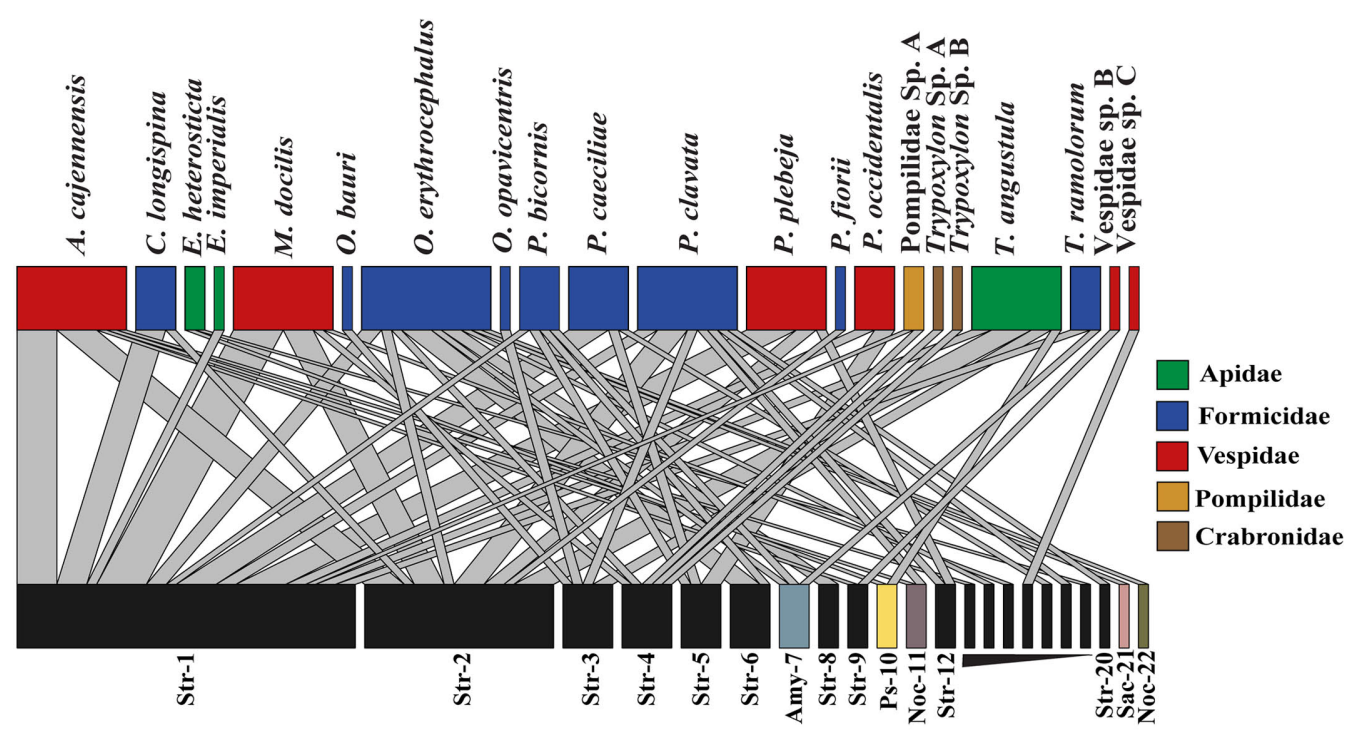

Actinobacteria

FIGURE 1 | Insect-Actinobacteria interaction network using OTUs clustering with $2 \%$ cut-off sequence similarity. Upper level boxes represent insect species and lower level boxes depict associated Actinobacteria OTUs. Boxes and link size are proportional to the total number of isolates obtained and to the frequency of this particular interaction, respectively. Genera are abbreviated as follow: Streptomyces (Str), Pseudonocardia (Ps) Amycolatopsis (Amy) Nocardia (Noc) Saccharothrix (Sac).

was only unsuccessful for species where sampling involved only a single colony, except in the case of the bee Trigona sp. 1 In comparing bees ( 34 colonies), ants (92 colonies), wasps (44 colonies), 23, 82, and 70 strains of Actinobacteria, were isolated respectively. By grouping the isolates according to the colony component from which they were obtained, 74 corresponded to adult insects (176 samples), 68 with immature insects (131 samples), and 45 with nest material (149 samples). In addition, from the stingless bee T. angustula other bee hive components were sampled and isolates obtained as follow: three from honey, one from brood comb, one from pollen and five from propolis (Table 1).

From the 197 Actinobacteria-like isolates obtained, we choose only unique morphotypes per colony component sampled (174), for DNA extraction and 16S rRNA sequence analysis. From those isolates 161 successfully amplified, 23 were replicates, and 138 Actinobacteria sequences were chosen for further analysis. A sequence alignment was generated and then 44 short sequences were removed and the remaining 94 were clustered into 22 different OTUs with a $2 \%$ cutoff used as an indicator of bacterial species (Figure 1, see Supplementary Table S1 for details about the distribution of isolates differentiating their origin) (Hong et al., 2006; Hulcr et al., 2011). Interaction network analysis using OTUs clustering did not show evidence of specific associations between Actinobacteria isolates and the insect species from which they were obtained (Figure 1). Streptomyces isolates were grouped into 22 different OTUs with ten of them being represented by singletons (Figure 1). Six dominant Streptomyces
OTUs accounted for $75 \%$ of all sequences included in the analysis. Two Pseudonocardia strains associated with bees and three Amycolatopsis strains associated with ants were also found. Within the Actinobacteria genus Nocardia, one strain was isolated from a bullet ant $(P$. clavata) and wasp larvae (A. cajennensis) and a different strain obtained from nest material of a trap-jaw ant colony (O. erythrocephalus). Additionally, one Sacchrothrix strain was isolated from O. erythrocephalus larvae (Figure 1).

Four main clades of Actinobacteria, each one composed of sequences with $99 \% 16 \mathrm{~S}$ rRNA identity were found to be associated with different groups of insects under study (Figure 2). In general, phylogenetic analysis of gyrB, grouped representative sequences from the $16 \mathrm{~S}$ rRNA tree in the same clades (Figures 2,3). In the $16 \mathrm{~S}$ rRNA phylogenetic tree, the paraphyletic group I represents a single 16S rRNA phylotype isolated repeatedly from 29 different samples, from nine different hymenopteran insect species (Figure 2). This group contained 16 Streptomyces isolates associated with vespid wasp colonies, 11 from ants and 2 from the stingless bee T. angustula. The closest relatives to this group were S. fulvissimus DSM 43, S. flavogriseus ATCC 33331, S. globisporus KTC 9026 and S. cavourensis NRRL 2740 , based on $>99 \%$ sequence similarity. Moreover, sequences from other studies corresponding to known host associated Streptomyces strains with antimicrobial (Poulsen et al., 2011) or cellulolytic activity (Book et al., 2016) were clustered in clade I (Figure 2). In the gyrB phylogeny, representative sequences within clade I were resolved into different taxonomic groups 

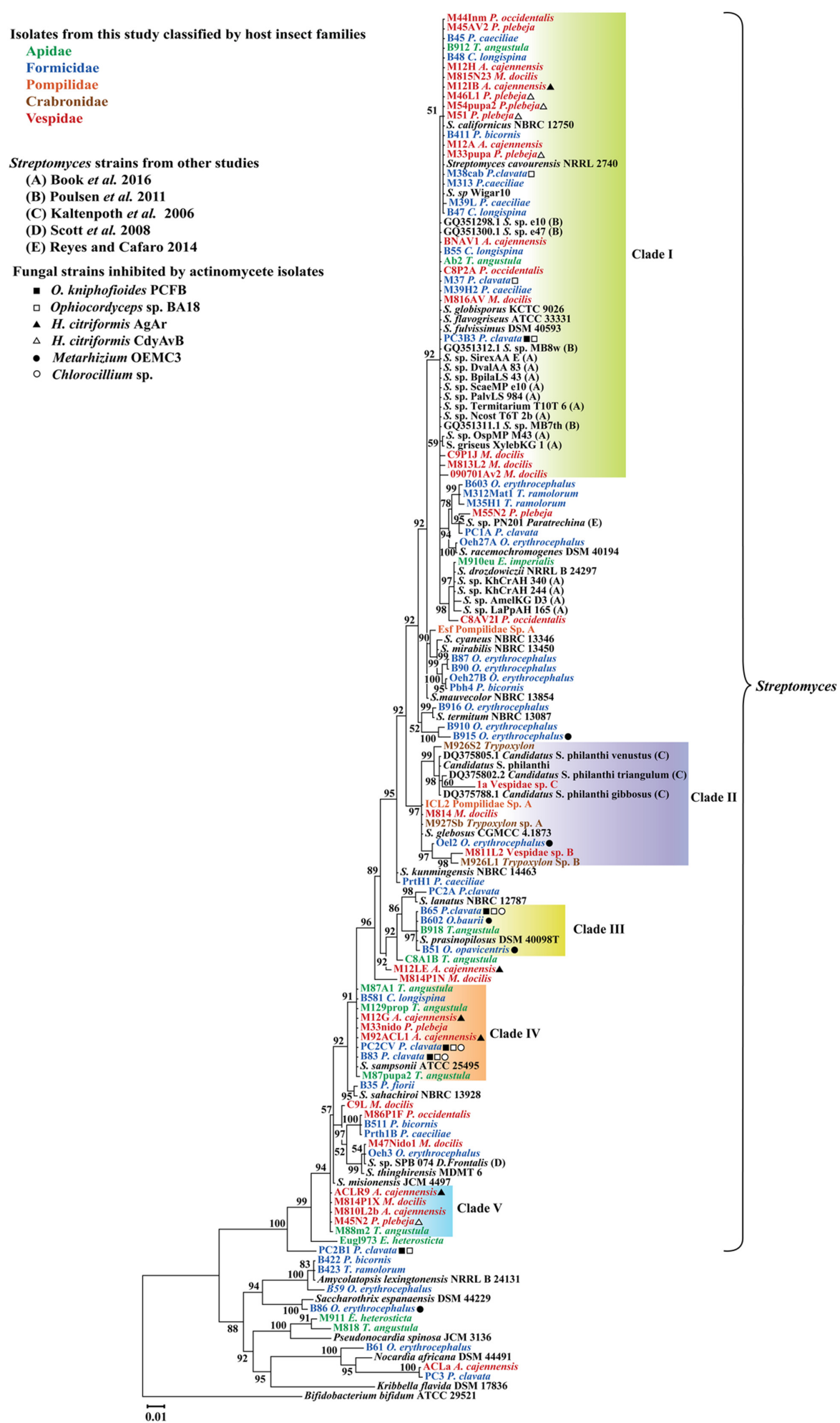

FIGURE 2 | Bayesian, phylogenetic analysis of 16S rRNA sequences of Actinobacteria associated with different hymenopteran insect species. Insect taxonomic identity is indicated next to sample code. Posterior probabilities (PP) are indicated at the corresponding nodes. NCBI reference sequences included in the analysis are denoted by the corresponding type culture collection acronym. Clades within $99 \%$ sequence similarity cutoff are highlighted except for clade II that it is composed of different phylotypes and was highlighted to show a group of sequences closely related to the well-studied solitary wasp symbiont Candidatus Streptomyces philanthi. Alignment 950 pb. 


\section{Isolates from this study classified by host insect families}
Apidae
Formicidae
Pompilidae
Crabronidae
Vespidae

\section{Streptomyces strains from other studies}

(A) Book et al. 2016

(E) Kaltenpoth et al. 2014

\section{S. griseus KCTC}

$S$. XylebKG 1
M813L2 M. docilis

M813L2 M. docilis
59 M37T P. clavata

59 M37T $P$. clavata
C9P1J $M$. docilis

C9P1J M. docilis
B56 C. longispina

C8P2A P. occidenatlis boheman

BNAV1 A. cajennensis

M46L1 P. plebeja

94 86 B912 T. angustula

M44LNM P. occidentalis boheman

M45LNM P. occide

B45 P. caeciliae

$\mathrm{B} 48$ C. longispina
$\mathrm{M} 12 \mathrm{H}$ A. cajennensis
$\mathrm{M} 100$

$41002 \mathrm{~A}$ A. cajennensis

M816AV M. docilis

94 U. parvas NBRC 14599

S. par. Termitarium T10T 6 (A)

$L$ S. albovinaceus NBRC 12739

$94\left[\begin{array}{c}\text { S. albovinaceus } \\ \text { S. anulatus DSM } 40128\end{array}\right.$

S. fulvissimus DSM 40593

${ }^{9} 6$ Streptomyces sp e83 (A)

S. cavourensis KCCM 40666

25100 M88M3P T. angustula

B420 T. ramulorum inrectum

100 M39L1 P. caeciliae

99 M33PUPA P. plebeja

M910EU $E$. imperialis

r $S$. sp. D Dor

3 S. sp. PalvLS 984 (A)

100 S. sp. SirexAA E (A)

99 S. sp. BpilaLS 43 (A)

S. gelaticus DSM 40065 (A)

S.viridiflavus KCTC 1997

$99-\begin{aligned} & \text { S.viridiflavus KCTC } 19975 \\ & - \text { M927SB Trypoxylon sp. A }\end{aligned}$

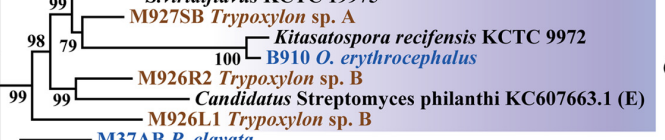

Canditus B

M926L1 Trypoxylon sp. B
M37AB P. clavata

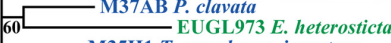

${ }_{100}$ - M35H1 T. ramolorum inrectu

100 S. albus DSM 41398

$100[$ S. nodosus ATCC 14899
M88M2 T. angustula

M83A2J T. angustula

S. antibioticus KCTC 9688

PHB1 P. bicornis

$81{ }_{100}^{\mathrm{B} 58 \text { C. longispin }}$

100 B33 P. fiorii

78 97 ACL9R A. cajennensis

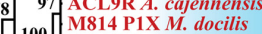

100 M810L2 A. cajennen

4 B918 T. angustula

99 B602 O. bauri

Clade V

96

\section{Clade III}

99 495 M52 P. plebeja

$100\left[\begin{array}{l}499 \\ \mathrm{~B} 41 \text { O. hastatus }\end{array}\right.$

72 S. olivochromogenes NRRL B1341

81- ARBIM02 T. angustula

5

$61 \quad$ PC1A P. clavata

9859 C8A1B T.angustula

$98-S$. tanashiensis KCTC 19972

orum inrectum

$-S$. venezuelae

— B603 O. bauri

-S. arenae strain NRRL 2377

${ }_{100}$ PBH 4 P. bicornis

100 PBH4 P. bicornis

OEH1 O. erythrocephalus

100 B94 O. erythrocephalus

$100[\mathrm{OEH} 3$ O. erythrocephalus

C9L M. docilis

82. M87A T. angustula

B581 C. longispina

B581 C. Iongispin
M33N P. plebeja

100 M129PROP T. angustula

B. sampsonii KJ40

\section{Clade IV}

$100 \div$ Saccharothrix espanaensis

Bifidobacterium bifidum ATCC 29521

0.1

FIGURE 3 | Bayesian, phylogenetic analysis of partial gyrB sequences of Streptomyces associated with different hymenopteran insect species. Insect taxonomic identity is indicated next to sample code. Posterior probabilities (PP) are indicated at the corresponding nodes. NCBI reference sequences included in the analysis are denoted by the corresponding type culture collection acronym. Representative isolates with 99\% sequence similarity cutoff in the $16 \mathrm{~S}$ rRNA phylogeny are highlighted as well as clade II that it is composed of different phylotypes. Clade II was highlighted to show a group of sequences closely related to the well-studied solitary wasp symbiont Candidatus Streptomyces philanthi. Alignment $780 \mathrm{pb}$. 


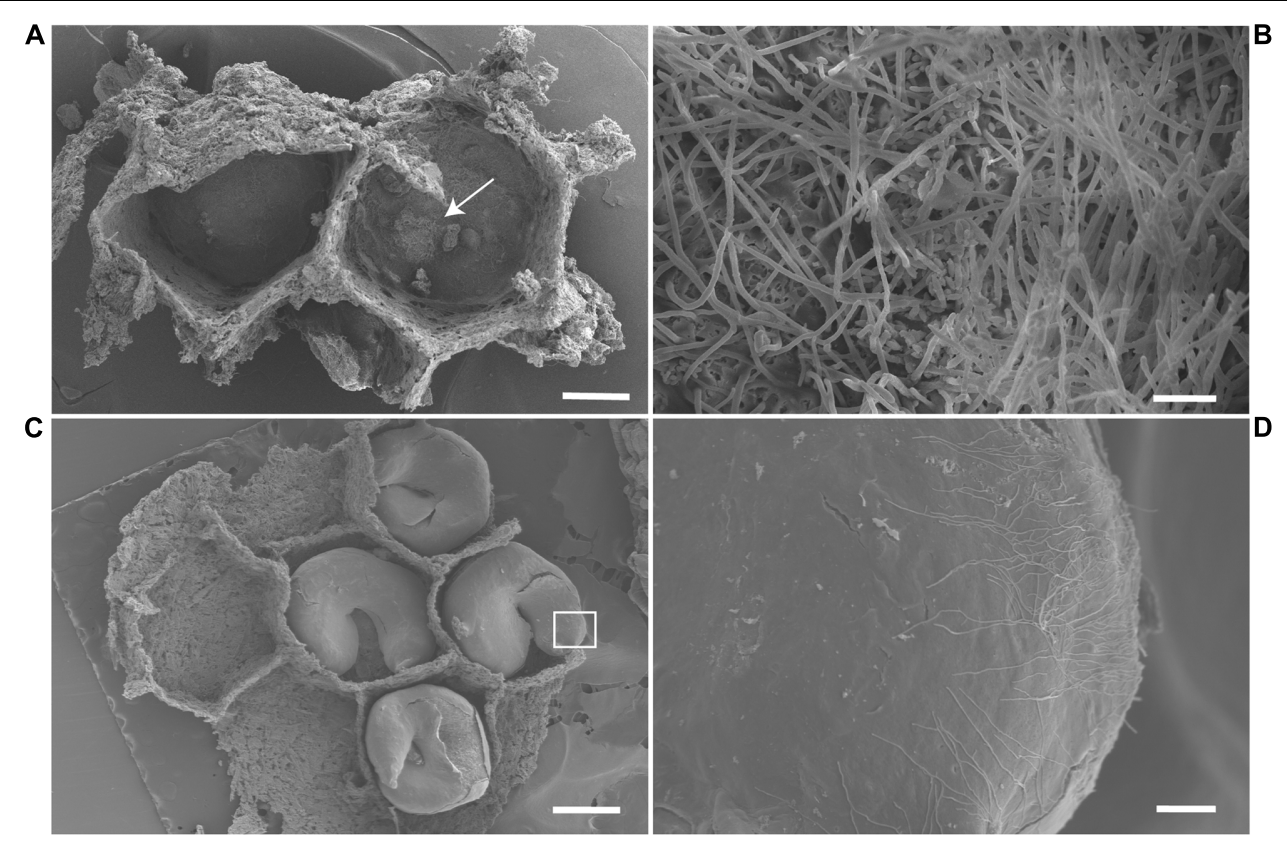

FIGURE 4 | SEM image of the interior of wasp brood chambers. (A) Two brood chambers of M. docilis, after larvae removal. Scale, 1 mm. (B) Filamentous bacteria forming a dense cluster at the base of the chamber, hyphae diameters of $1.3-2.4 \mu \mathrm{m}$. Scale, $20 \mu \mathrm{m}$. (C) P. plebeja larvae in brood chambers. Scale, $1 \mathrm{~mm}$. (D) Streptomyces like hyphae growing on P. plebeja larvae. Hyphae diameter of $1.2-1.7 \mu \mathrm{m}$. Scale, $60 \mu \mathrm{m}$.

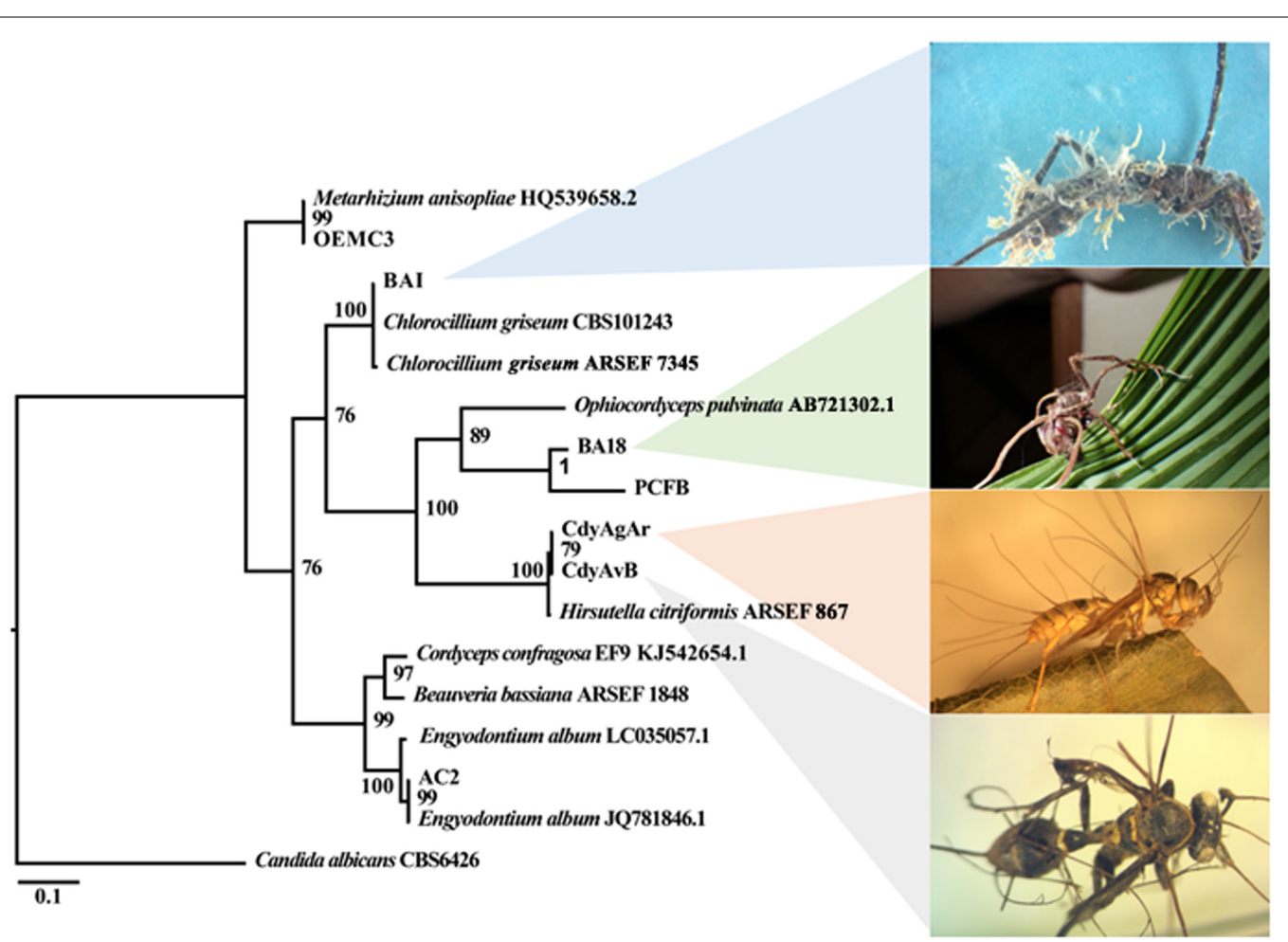

FIGURE 5 | Bayesian phylogenetic relationships among fungal isolates in this study as inferred from ITS-5.8S sequences. Posterior probability (PP) at the corresponding nodes. The tree was rooted on Candida albicans. 
A
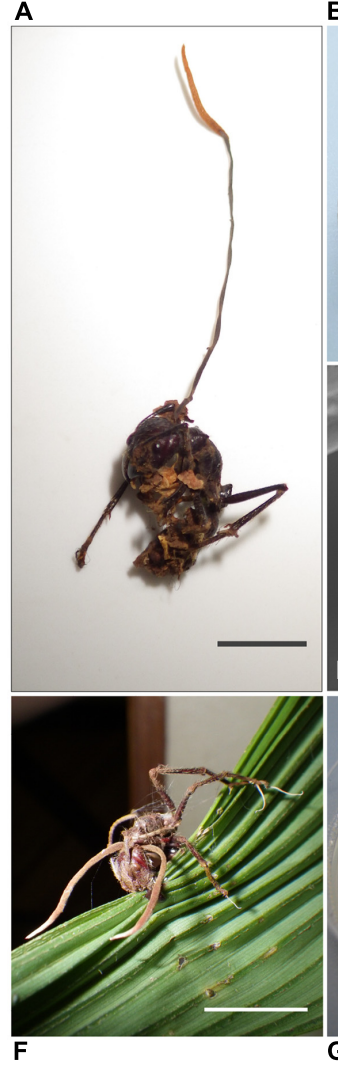

B
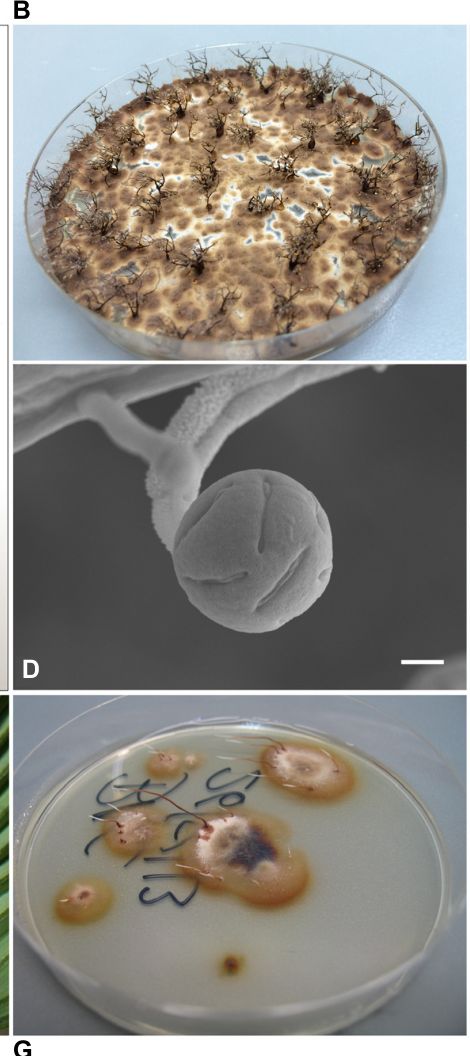

C

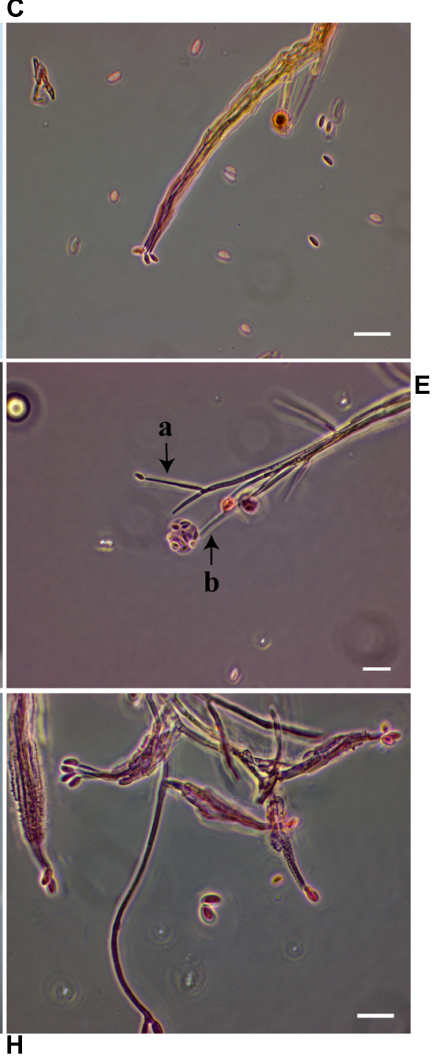

FIGURE 6 | Ophiocordyceps fungi infecting P. clavata ants. (A) Ophiocordyceps kniphofioides (H. stillbelliformis) PCFB in the sexual state. Scale, $1 \mathrm{~cm}$ (B) H. stilbelliformis PCFB isolate pure culture on PDA, showing dense growth of synnemata. (C) H. stilbelliformis PCFB ovoid conidia borne at compacted terminal phialides. Scale, $20 \mu \mathrm{m}$ (D) SEM micrograph of PCFB verrucose apical phialide with conidias inside mucous droplet. Scale, $4 \mu \mathrm{m}$. (E) a- and b- phialides and conidia of Hirsutella stilbelliformis PCFB. Scale, $20 \mu \mathrm{m}$. (F) P. clavata ant, infected by Ophiocordyceps sp. Scale, $1 \mathrm{~cm}$. (G) Isolate BA18 in PDA pure culture. (H) BA18, verrucose compact and apical phialides with ovoid conidia. Scale, $20 \mu \mathrm{m}$.

but within a single clade with the Streptomyces strains with high cellulolytic activity (Figure 3).

Clades III, IV, and V also represent different 16S rRNA phylotypes (99\% cut off) with their closest relatives being S. prasinopilosus, S. sampsonii, and S. misionensis, respectively. Sequences corresponding to Streptomyces isolates associated with subsocial Crabronidae or Pompilidae insects grouped together in the monophyletic Clade II (Figure 3) with Candidatus Streptomyces philanthi, the solitary wasp Philanthus triangulum symbiont (Kaltenpoth et al., 2005, 2014).

\section{Electron Microscopy for Actinobacteria Localization in Brood Chambers and Insect's Cuticle}

From the 24 Actinobacteria isolates associated with the wasps M. docilis, $62 \%$ were obtained from the nest substrate. Scanning electronic micrographs from brood chambers from two different $M$. docilis nests revealed the presence of filamentous microorganisms (Figure 4B). Vegetative hyphae with diameters of $1.3-2.4 \mu \mathrm{m}$ was abundant at the base of the brood chamber but was not observed externally (Figures 4A,B). In the case of the vespid wasp $P$. plebeja, six different colonies were studied from which were obtained 11 Streptomyces isolates associated with brood or nest samples. Four of these isolates were isolated from different colonies and grouped together as one 16S rRNA Streptomyces phylotype in Clade I (Figure 2), suggesting being a common strain associated with this wasp. The SEM ultrastructure of P. plebeja brood chambers was also studied and bacteria with Streptomyces morphology were found growing on the larvae (Figures 4C,D). These hyphae have diameters between 1.2 and $1.7 \mu \mathrm{m}$. The ultrastructure of adult $M$. docilis wasp cuticle was also studied; however, evidence of microorganism growth was not found. Similarly, no hyphae with morphology similar to Streptomyces were seen when samples from adults, immature stages, and nest material from the vespid A. cajennensis and adult ants within the species $O$. erythrocephalus and $P$. clavata were seen under SEM.

\section{Isolation and Identification of Entomopathogenic Fungi}

The ITS region from seven fungal isolates that were obtained from insect cadavers was successfully amplified and a phylogenetic tree was constructed (Figure 5). These 

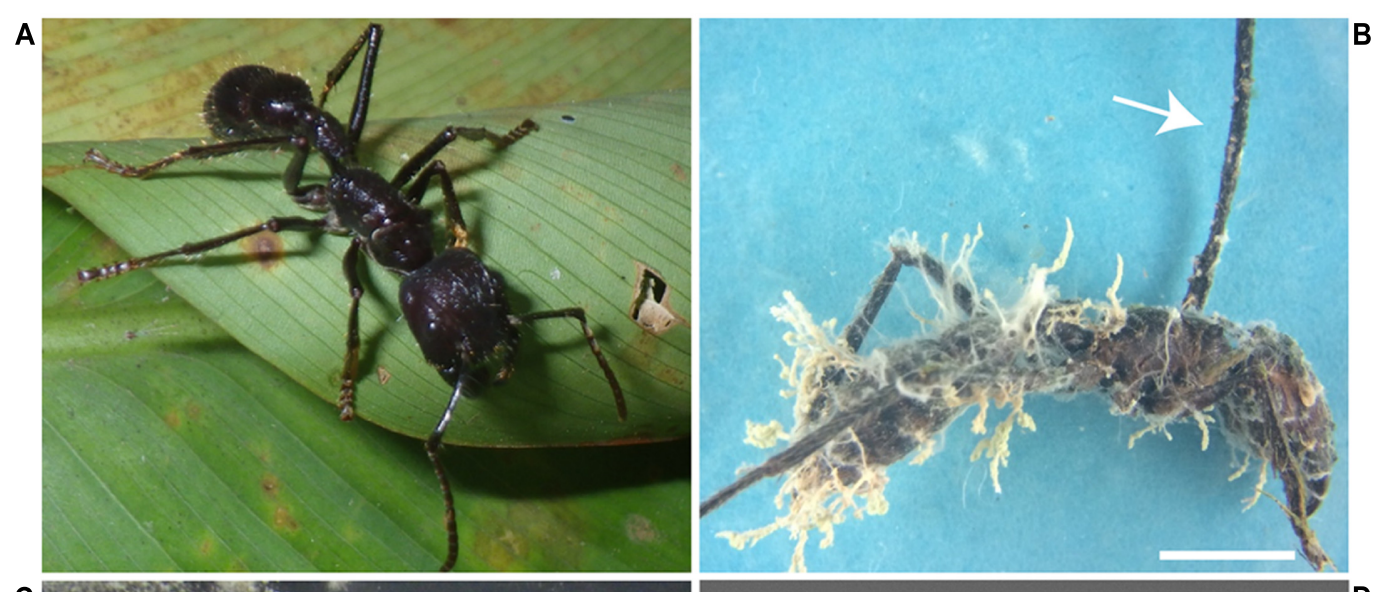

C
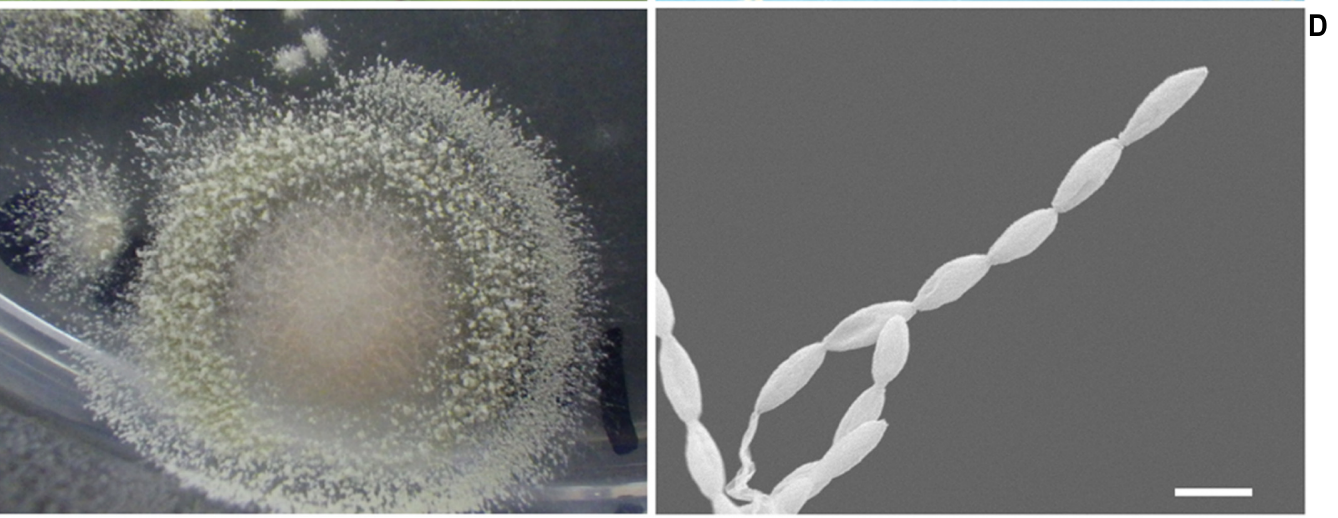

FIGURE 7 | Paraponera clavata ant parasitized by fungi. (A) Healthy P. clavata ant. (B) Infected ant, arrow pointing at the stroma that grew on the back of the ant's head with no perithecia, note the dense yellowish aerial hyphae with chains of conidia growing on the ant's body. Scale, 5 mm (C) Isolate BAI obtained from the P. clavata cadaver. (D) SEM micrograph, showing the conidia chains growing directly from the ant's infected body. Scale, $2 \mu \mathrm{m}$.

isolates grouped with the families Ophiocordycipitaceae, Metacordycipitacea, and other closely related groups.

PCFB and BA18, two fungal strains isolated from P. clavata ants were classified by macro and micromorphology as well as ITS, SSU and E- $1 \alpha$ sequences, within the Ophiocodycipitaceae family where all Cordyceps fungi infecting ants are grouped. Isolate PCFB was obtained from a specimen with fungal growth in its teleomorph stage, with a characteristic single brown stroma with orange fertile tip emerging from the back of the ant's head (Figure 6A). This isolate was identified as O. kniphofioides (H. stilbelliformis) with a $98 \%$ Ef- $1 \alpha$ sequence identity. Moreover, microscopic study of coordinated hyphal structures (synnemata) of isolate $\mathrm{PCFB}$, showed the presence of distinctive verrucose hyphae, phialides, and conidia (Figures 6B-E) (Evans and Samson, 1984). Isolate BA18 (Figure 6G) was obtained from a $P$. clavata ant attached by its mandibles to the underside of a palm leaf (Figure 6F) and the fungus was growing out of the ant's body in its anamorphic state. Isolate BA18 was recognized as a close relative to O. kniphofioides sharing 95\% Ef- $1 \alpha$ and $98 \% 18$ S partial sequence similarity when compared against the closest relatives sequence available at NCBI database. Conidiophores and conidia structures similar to isolate PCFB were found when the micromorphology of BA18 synnemata
(Figure 6H) was examined. A Metarhizium strain isolated from an $O$. erythrocephalus ant, was included in our entomopathogen collection. This asymptomatic specimen was collected in the field and brought to the lab and later died developing Metarhizium like fungal growth. The identity of this fungus was confirmed by ITS sequence.

BAI was an isolate obtained from an apparently hyperparasitized $P$. clavata specimen presenting a brown dried stroma stalk extending from the back of the ant's head and a dense yellowish aerial mycelium with spores growing out from the joints of the cadaver (Figure 7). Isolate BAI was grouped together with Chlorocillium spp. by its ITS and 18S gene sequencing. Isolates CdyAgAr and CdyAvB, obtained from wasp specimens collected at San Carlos were identified as Hirsutella sp. (Figure 8). For these isolates, ITS and 18S rRNA genes were sequenced, and both genes shared 99\% identity with $H$. citriformis when compared against sequences from NCBI databases. Sequence similarity, as well as macro and microscopic morphology examination, suggest that both wasp specimens were infected by the same fungal species. Finally, a fungal isolate classified by ITS and SSU sequences as Engyodontium sp. was included in the study. This isolate was obtained from an Agelaia wasp cadaver infected by an Ophiocordyceps fungus that 
A

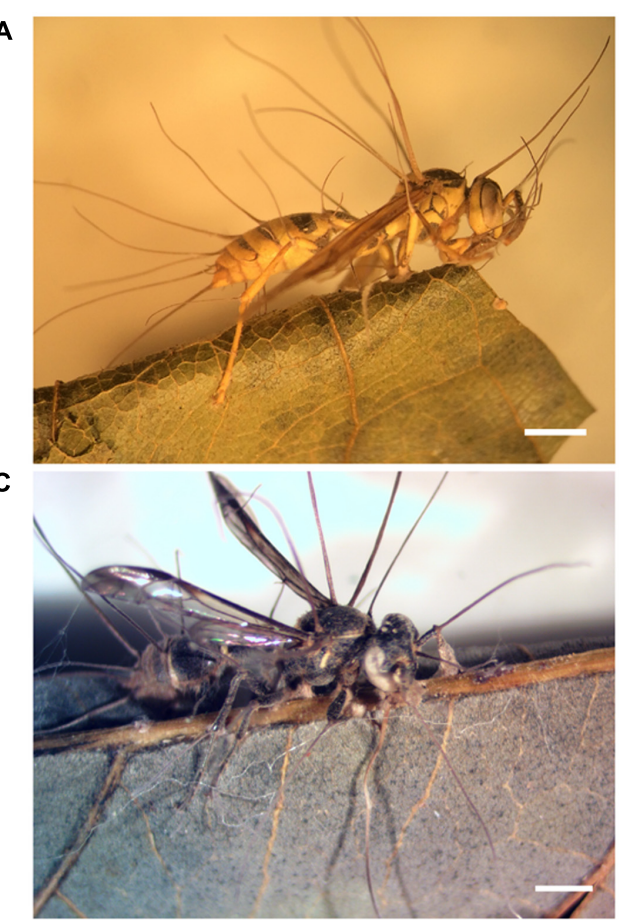

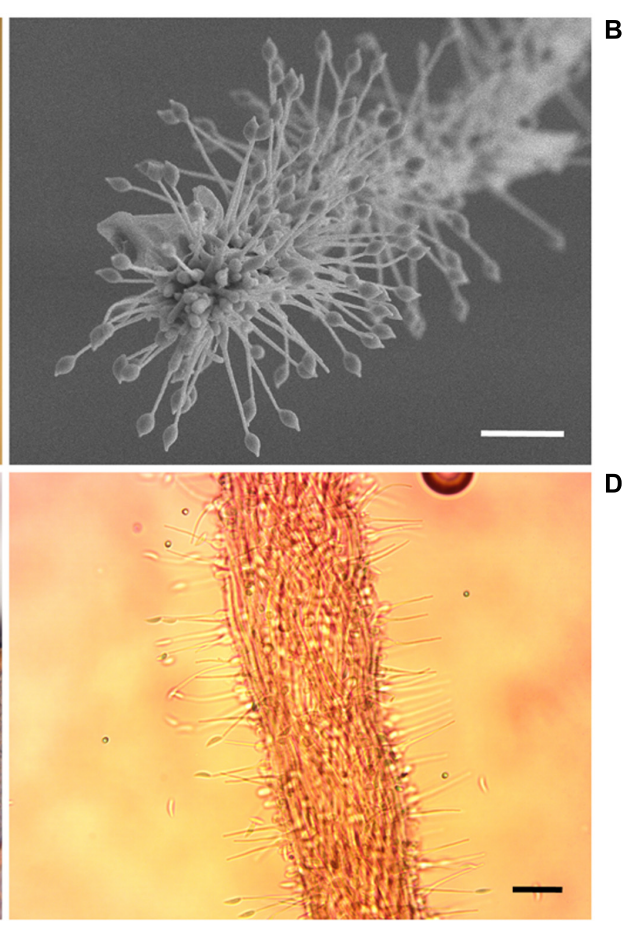

B

FIGURE 8 | Wasps infected with Hirsutella fungi. (A) A. areata cadaver. Note solitary stromata, filiform, arising from thorax to the abdomen region of the host, erect or curved and of brown color. Scale, $2 \mathrm{~mm}$. (B) Ultrastructure of stromata from isolate CdyAgAr showing phialides and citriform conidia. Scale, $20 \mu \mathrm{m}$. (C) Polybia sp. wasp attached to a leaf by their mandibles. Scale, $1 \mathrm{~mm}$. (D) Light micrograph of stromata from CdyAVB isolate in PDA pure culture. Scale, $20 \mu \mathrm{m}$.

was collected at La Selva in November 2014. Although, to our knowledge there is no evidence of Engyodontium fungus being pathogens of hymenopteran insects, there have been reports of this fungal genus being a pathogen of another insect group (Samson et al., 2013).

\section{Bioassays: Actinobacteria Strains with Antifungal Properties against Insects' Natural Enemies of Fungal Origin}

In total 125 bioassays were carried out in duplicates between Actinobacteria and entomopathogenic fungi. Only some of the Actinobacteria isolates were used in bioassays and were chosen so that both the bacteria and the fungi were obtained from the same insect host, at the species or genus level. These bioassays were categorized into seven different groups each one corresponding to a different fungus. For every group of bioassays, at least three different Actinobacteria isolates that could inhibit the growth of the pathogenic fungi in vitro (Figure 9) were found. The highest proportion of antifungal activity was seen for bioassays between P. clavata Actinobacteria and the fungal isolate BA18. In this group of bioassays, 10 out 12 Actinobacteria isolates inhibited the growth of the Ophiocordyceps fungus. In the case of P. clavata Actinobacteria and the PCFB (O. kniphofioides) fungal isolate, 8 out 15 bacterial isolates produced halos of inhibition. Similarly, in A. cajennensis and Hirsutella bioassays, 12 out of 23 isolates presented antifungal activity.
All Actinobacteria isolates with antifungal activity that had their 16S rRNA sequence included in the phylogenetic study were mapped in the tree (Figure 2). From the four Actinobacteria isolates not belonging to the genus Streptomyces that were screened for antifungal properties, only B86 (identified in the genus Saccharothrix) was effective in inhibiting the growth of the fungal strain that was tested against (Metarhizium).

\section{DISCUSSION}

Our results indicate that Actinobacteria associations with hymenopteran insects are more common than previously described (Currie et al., 1999; Kaltenpoth et al., 2005; Promnuan et al., 2009; Poulsen et al., 2011; Madden et al., 2013; Reyes and Cafaro, 2014). With SEM analysis, the presence of filamentous microorganisms with cell morphology similar to Streptomyces inside $M$. docilis and $P$. plebeja brood chambers (Figure 4) were confirmed. Moreover, Actinobacteria from most insect species sampled were successfully isolated, including insects from five different Hymenopteran families, which represent eusocial (paper wasps, ants, and the stingless bee, T. angustula) and non-eusocial lifestyles (orchid bees, mud dauber wasps in the family Crabronidae and a spider wasp in the family Pompilidae). The highest proportion of isolates per colony was obtained in Trypoxylon sp. wasps, followed by paper wasps in the tribe Epiponini ( $M$. docilis, P. plebeja, P. occidentalis, and A. cajennensis). In these cases, Actinobacteria were isolated 
from all colony compartments sampled (brood, adults and nest material). This was also the case for ant species such as O. erythrocephalus, C. longispina, $P$. caeciliae, and T. ramulorum inrectum. On the other hand, with the exception of the meliponid bee Trigona sp. 1 (four colonies sampled), all insect species that did not yield Actinobacteria were sampled only once. In the case of Trigona bees, only adults and material from nest entrances were sampled, as the colonies studied were located inside tree trunk cavities. It is possible that no Actinobacteria were isolated from Trigona bees because of the inability to sample other colony components. It has been suggested that the role of defensive Actinobacteria symbionts could be linked to specific vulnerable life stages of their host (e.g., larvae and pupae; Kaltenpoth and Engl, 2013). Likewise, in a different study, Promnuan et al. (2009) reported the isolation of Actinobacteria from brood cells of Trigona bee hives. Consequently, we obtained 12 actinomycete isolates from the internal colony components of a related stingless bee, T. angustula.

Streptomyces was the predominant genus of culturable Actinobacteria associated with insect colonies in the present study. These results are consistent with similar studies employing culture-dependent isolation approaches in Apis and Trigona bees (Promnuan et al., 2009), Dendroctonus beetles (Hulcr et al., 2011), Polistes dominulus wasps (Madden et al., 2013) and Pseudomyrmex penetrator, Petalomyrmex phylax, and Crematogaster margaritae ants as well as culture-independent techniques, as the case for P. longicornis (Reyes and Cafaro, 2014). Moreover, our interaction network analysis suggests that the dominant Streptomyces phylotypes had diverse associations with hymenopteran hosts at both the genus and family levels (Figure 1). The binning of isolates from different insect groups into a few OTUs imply that possible horizontal transmission and selective processes may have occurred. These results agree with other well-studied insectActinobacteria defensive symbiosis in which the symbiont has undergone dynamic substitution over the evolutionary history of their host (Kaltenpoth et al., 2010, 2012; Cafaro et al., 2011; Kaltenpoth and Engl, 2013). Although some Actinobacteria strains classified into genera different than Streptomyces were isolated, our culture-dependent screening approach may have underestimated the insect host Actinobacteria diversity. Independent cultivation techniques are necessary to address the real diversity, abundance and stability of Actinobacteria in these systems.

Our results indicate that $1 / 3$ of all the isolates obtained in our sampling occur within clade I of our $16 \mathrm{~S}$ rRNA phylogenetic tree. This clade corresponds to a lineage of highly cellulolytic Streptomyces previously identified in temperate zones, which is associated with a variety of insect species that feed on plant biomass (Book et al., 2016). The high cellulolytic activity present in these bacteria appears to be the result of evolutionary adaptations acquired through horizontal transfer and selective retention of genes as well as the expansion of their regulatory elements (Book et al., 2016). Further studies evaluating the cellulolytic activity and genomic content enrichment for key enzyme families related to plant biomass degradation in our isolates from clade I would provide important insight into this

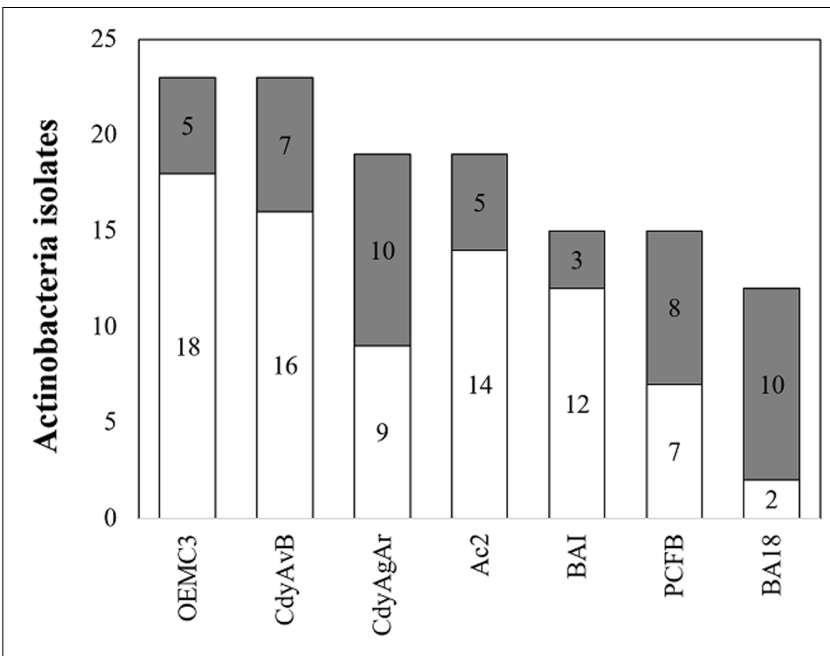

Entomopathogenic fungi isolates

FIGURE 9 | Actinobacteria isolates with antifungal properties against entomopathogenic fungi. In gray, the number of isolates with antifungal properties are shown and in white the ones without activity. OEMC3 (Metarhizium isolate against Actinobacteria obtained from Odontomachus ants), CdyAgAR (H. citriformis isolate against Actinobacteria obtained from A. cajennensis), CdyAvB (H. citriformis against Actinobacteria isolated form $P$. occidentalis y P. plebeja wasps), AC2 (Engyodontium sp. against Actinobacteria associated with $A$. cajennensis), BAl (Chlorocillium sp. challenged against $P$. clavata Actinobacteria isolates), PCFB (O. kniphofioides against $P$. clavata Actinobacteria) y BA18 (Ophiocordyceps sp. against $P$. clavata Actinobacteria).

potential nutritional role of these Actinobacteria in their host niche.

To test the resolution of our $16 \mathrm{~S}$ rRNA tree, the gyrB gene from representative isolates included in our 16S rRNA phylogeny were amplified and sequenced. Our 16S rRNA and gyrB phylogenies had corresponding sequences grouped in the same clades with minor changes related to more variability in sequence composition in clade I from the gyrB tree (Figure 3). As pointed out elsewhere, among important housekeeping genes markers, gyrB produced higher correlations with genome relatedness in phylogenetic analysis with Actinobacteria belonging to the Streptomycetaceae family (Han et al., 2012). When comparing the phylogenetic trees, there is evidence of apparently unique phylotypes represented in clades III, IV, and V (Figures 2, 3) in both phylogenies. These monophyletic clades consist of one taxonomic unit that was isolated repeatedly from different insect hosts. Moreover, isolates within these clades that were included in bioassays showed antifungal properties against different pathogenic fungi, suggesting that these isolates shared similarities in terms of production of antifungal compounds active against natural enemies of their host.

Our phylogenetic analysis results also suggest that subsocial wasps included in our study and the Streptomyces isolates obtained from them are taxonomically related to $P$. triangulum and its mutualistic symbiont $\mathrm{Ca}$. Streptomyces philanthi respectively, showing congruency in both Actinobacteriainsect association systems. These findings require further 


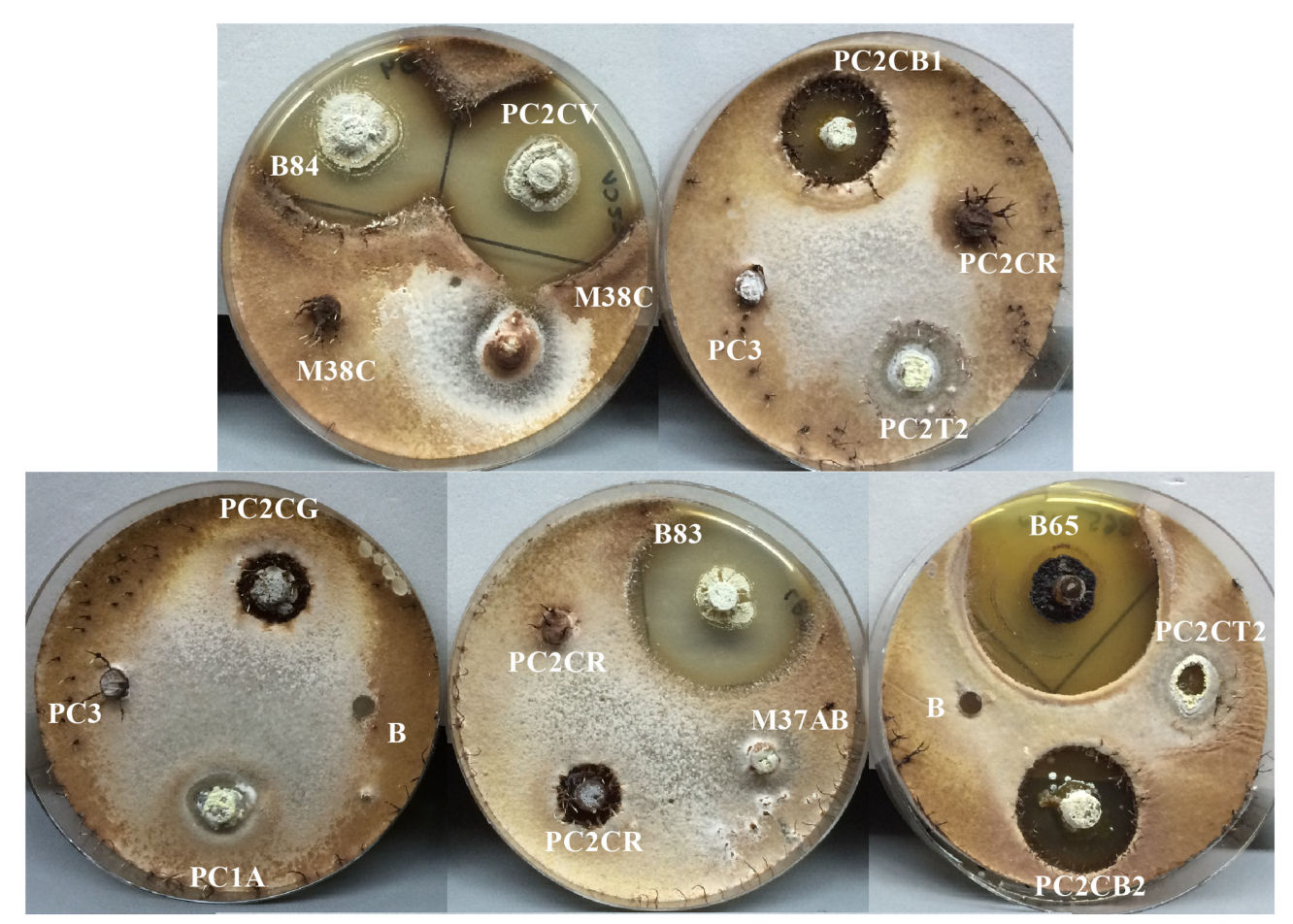

FIGURE 10 | Bioassay, antifungal activity screening from Actinobacteria isolates associated with $P$. clavata against $O$. kniphofioides. The Actinobacteria isolate codes are shown. Negative controls are marked with the letter "B." For illustrative purposes the photographs were taken after 4 weeks of incubation because of the slow growing of this fungus.

study, as the P. triangulum-Streptomyces defensive symbiosis is thought to be confined into the subfamily Philanthinae (Kaltenpoth et al., 2012), whereas Trypoxylon is a genus belonging to the subfamily Crabroninae. Both of these subfamilies are classified in different monophyletic clades in the diverse paraphyletic family Crabronidae (Debevec et al., 2012).

One important goal of this study was to test if the Actinobacteria associated with insects can protect them against natural enemies. Different strains of Ophiocordyceps (Hirsutella) fungi were isolated and blastospores were obtained in high concentrations to screen for Actinobacteria antifungal activity in vitro. All of the insect species examined (those from which entomopathogenic fungi were isolated) had more than three different associated Actinobacteria strains that were capable of producing zones of inhibition in co-culture in vitro bioassays (Figure 9).

Cordyceps fungi are characterized by being host specialized parasites. For example, the zombie ant fungus Ophiocordyceps unilateralis is an antagonist of ants in the tribe Camponotini (Formicinae, Formicidae), with less common infections reported on Polyrhachis ants (Pontoppidan et al., 2009; Andersen et al., 2012). Similarly, Ophiocordyceps kniphofioides infects Cephalotes atratus (Formicidae: Myrmicinae), Paraponera clavata, and Dinoponera longipes (Formicidae: Ponerinae) ants (Evans and Samson, 1982; Sanjuan et al., 2015). In this study, it has been shown that different strains of Streptomyces isolated from $P$. clavata ants could inhibit the ant's parasitic fungus O. kniphofioides (Figure 10).

Two H. citriformis (Ophiocordycipitaceae: Hypocreales) strains were isolated from two different vespid wasps (Figure 8). Hirsutella is a genus of anamorphic fungi whose teleomorphs has commonly been linked to the genus Ophiocordyceps (Sung et al., 2007). H. citriformis is a known pathogen of insects in the orders Hemiptera and Psocoptera (Simmons et al., 2015). To our knowledge, this is the first report on $H$. citriformis infecting Hymenopteran insects. In this study, H. citriformis was also inhibited by several wasp associated Actinobacteria strains. Our results suggest that the antifungal substances produced by symbiotic Actinobacteria may occur in the natural environment, but additional studies are necessary to demonstrate their presence.

This study shows associations of a few Streptomyces lineages with diverse neotropical hymenopteran insects, one of them being previously described in temperate zones, suggesting a consistent association that spans from temperate to tropical regions. Moreover, the results of the present study provide evidence of antagonism between some Actinobacteria strains and the fungal entomopathogens tested and supports the idea that certain insects may use some of the active secondary metabolites from associated Actinobacteria as an additional protection mechanism against natural enemies. Collectively, these findings provide insight into the widespread and dynamic host-niche selection of Actinobacteria and points to promising 
models of mutualistic symbiosis, which harbor great potential in finding new biologically active compounds with medical and biotechnological applications.

\section{AUTHOR CONTRIBUTIONS}

Conceived and designed the experiments: CC, AP-T, MM, and BM-C. Performed the experiments: BM-C. Processed SEM samples: RM-S. Analyzed the data: BM-C, CC, and AP-T. Contributed reagents/materials/analysis tools: CM-C and MM. Wrote the paper: BM-C, CC, and AP-T.

\section{FUNDING}

Authors gratefully acknowledge financial support from the National Science Foundation, United States (MCB-0702025), Sistema de Estudios de Posgrado y Vicerrectoría de Investigación de la Universidad de Costa Rica (research projects 801-B0-538 and 810-B3-185), and the National Institute of Health, United States (U19 Al109673).

\section{ACKNOWLEDGMENTS}

Collecting permits were granted by the "Comisión Institucional de Biodiversidad” (Institutional Biodiversity Committee,

\section{REFERENCES}

Aguiar, A. P., Deans, A. R., Engel, M. S., Forshage, M., Huber, J. T., Jennings, J. T., et al. (2013). Order Hymenoptera. Zootaxa 3703, 51-62. doi: 10.1603/EN09221 Alves, E., Gilvaine Ciavareli, L., Ampélio Pozza, E., and de Carvalho, M. (2013). "Scanning electron microscopy for fungal sample examination," in Laboratory Protocols in Fungal Biology: Current Methods in Fungal Biology, eds G. V. Kumar, M. G. Tuohy, M. Ayyachamy, K. M. Turner, and A. O'Donovan (New York, NY: Springer), 133-150. doi: 10.1007/978-1-4614-2356-0_8

Andersen, S. B., Ferrari, M., Evans, H. C., Elliot, S. L., Boomsma, J. J., and Hughes, D. P. (2012). Disease dynamics in a specialized parasite of ant societies. PLOS ONE 7:e36352. doi: 10.1371/journal.pone.0036352

Barka, E. A., Vatsa, P., Sanchez, L., Gaveau-Vaillant, N., Jacquard, C., Klenk, H.-P., et al. (2016). Taxonomy, physiology, and natural products of Actinobacteria. Microbiol. Mol. Biol. Rev. 80, 1-43. doi: 10.1128/MMBR.00019-15

Bawa, K. S., McDade, L. A., and Hespenheide, H. (1994). La Selva: Ecology and Natural History of a Neotropical Rain Forest. Chicago, IL: University of Chicago Press.

Bérdy, J. (2005). Bioactive microbial metabolites. J. Antibiot. 58, 1-26. doi: 10.1038/ ja. 2005.1

Berg, R. (1996). The indigenous gastrointestinal microflora. Trends Microbiol. 4, 430-435. doi: 10.1016/0966-842X(96)10057-3

Bhattacharya, D., Nagpure, A., and Gupta, R. K. (2007). Bacterial chitinases: properties and potential. Crit. Rev. Biotechnol. 27, 21-28. doi: 10.1080/ 07388550601168223

Book, A. J., Lewin, G. R., McDonald, B. R., Takasuka, T. E., Wendt-Pienkowski, E., Doering, D. T., et al. (2016). Evolution of high cellulolytic activity in symbiotic Streptomyces through selection of expanded gene content and coordinated gene expression. PLOS Biol. 14:e1002475. doi: 10.1371/journal.pbio.1002475

Boomsma, J. J., Jensen, A. B., Meyling, N. V., and Eilenberg, J. (2014). Evolutionary interaction networks of insect pathogenic fungi. Annu. Rev. Entomol. 59, 467-485. doi: 10.1146/annurev-ento-01163-162054

Bot, A., Ortius-Lechner, D., Finster, K., Maile, R., and Boomsma, J. J. (2002). Variable sensitivity of fungi and bacteria to compounds produced by the
University of Costa Rica; Resolution Number 012); and authorized by La Selva Biological Station and Las Brisas Nature Reserve. The authors thank Dr. Shanna Gofredi, Dr. Sean O'Donnell, and Dr. Ralph Saporito for critical comments on the manuscript and Dr. Fernando García and Dr. César Rodríguez for advice and support. Terry McGlynn for facilitating the use of personal laboratory equipment and Dr. Carlos García Robledo for help on interaction network analysis. Ludovic Le Renart and David Hughes for advice on fungal taxonomy and physiology. Ronald Vargas for field work and insect identification. Natalie Whitehead, Jane Li, and Mauricio García for field assistance. Danilo Brenes, Jessica Smith, Marcela Fernandez, Mariel Víquez and many other members of the "Grupo de Investigación Simbiosis Hospedero-Microorganismo" for their help with lab work. Dr. Deedra McClearn, Dr. Carlos de la Rosa and staff members of La Selva Biological Station (Organization for Tropical Studies) for logistic support on field and lab work on site; MSc. Ethel Sánchez for advice on electron microscopy and to the scientific personnel at CIEMic and CIBCM, Universidad de Costa Rica, for providing the use of research facilities.

\section{SUPPLEMENTARY MATERIAL}

The Supplementary Material for this article can be found online at: https://www.frontiersin.org/articles/10.3389/fmicb. 2017.02016/full\#supplementary-material

metapleural glands of leaf-cutting ants. Insectes Soc. 49, 363-370. doi: 10.1007/ PL00012660

Cafaro, M. J., and Currie, C. R. (2005). Phylogenetic analysis of mutualistic filamentous bacteria associated with fungus-growing ants. Can. J. Microbiol. 51, 441-446. doi: 10.1139/w05-023

Cafaro, M. J., Poulsen, M., Little, A. E. F., Price, S. L., Gerardo, N. M., Wong, B., et al. (2011). Specificity in the symbiotic association between fungus-growing ants and protective Pseudonocardia bacteria. Proc. Biol. Sci. 278, 1814-1822. doi: 10.1098/rspb.2010.2118

Cardinal, S., Danforth, B. N., Pitts, J., Gillespie, J., and Cameron, S. (2011). The antiquity and evolutionary history of social behavior in bees. PLOS ONE 6:e21086. doi: 10.1371/journal.pone.0021086

Currie, C. R., Poulsen, M., Mendenhall, J., Boomsma, J. J., and Billen, J. (2006). Coevolved crypts and exocrine glands support mutualistic bacteria in fungusgrowing ants. Science 311, 81-83. doi: 10.1126/science.1119744

Currie, C. R., Scott, J. A., Summerbell, R. C., and Malloch, D. (1999). Fungusgrowing ants use antibiotic-producing bacteria to control garden parasites. Nature 398, 701-704. doi: 10.1038/19519

Darriba, D., Taboada, G. L., Doallo, R., and Posada, D. (2012). jModelTest 2: more models, new heuristics and parallel computing. Nat. Methods 9, 772. doi: 10.1038/nmeth.2109

de Bekker, C., Quevillon, L. E., Smith, P. B., Fleming, K. R., Ghosh, D., Patterson, A. D., et al. (2014). Species-specific ant brain manipulation by a specialized fungal parasite. BMC Evol. Biol. 14:166. doi: 10.1186/s12862-014-0166-3

de Souza, D. J., Bézier, A., Depoix, D., Drezen, J.-M., and Lenoir, A. (2009). Blochmannia endosymbionts improve colony growth and immune defence in the ant Camponotus fellah. BMC Microbiol. 9:29. doi: 10.1186/1471-21 80-9-29

Debevec, A. H., Cardinal, S., and Danforth, B. N. (2012). Identifying the sister group to the bees: a molecular phylogeny of Aculeata with an emphasis on the superfamily Apoidea. Zool. Scr. 41, 527-535. doi: 10.1111/j.1463-6409.2012. 00549.x

DeMera, J. H., and Angert, E. R. (2004). Comparison of the antimicrobial activity of honey produced by Tetragonisca angustula (Meliponinae) and Apis mellifera 
from different phytogeographic regions of Costa Rica. Apidologie 35, 411-417. doi: 10.1051/apido:2004033

Dillon, R. J., and Dillon, V. M. (2004). The gut bacteria of insects: nonpathogenic interactions. Annu. Rev. Entomol. 49, 71-92. doi: 10.1146/annurev.ento.49. 061802.123416

Dormann, C., Gruber, B., and Fründ, J. (2008). Introducing the bipartite package: analysing ecological networks. R News 8, 8-11.

Evans, H. C., and Samson, R. A. (1982). Cordyceps species and their anamorphs pathogenic on ants (Formicidae) in tropical forest ecosystems I. The Cephalotes (Myrmicinae) complex. Trans. Br. Mycol. Soc. 79, 431-453. doi: 10.1016/S00071536(82)80037-5

Evans, H. C., and Samson, R. A. (1984). Cordyceps species and their anamorphs pathogenic on ants (Formicidae) in tropical forest ecosystems II. The Camponotus (Formicinae) complex. Trans. Br. Mycol. Soc. 82, 127-150. doi: 10.1016/S0007-1536(84)80219-3

Evans, J. D., and Lopez, D. L. (2004). Bacterial probiotics induce an immune response in the honey bee (Hymenoptera: Apidae). J. Econ. Entomol. 97, 752-756. doi: 10.1093/jee/97.3.752

Han, J. H., Cho, M. H., and Kim, S. B. (2012). Ribosomal and protein coding gene based multigene phylogeny on the family Streptomycetaceae. Syst. Appl. Microbiol. 35, 1-6. doi: 10.1016/j.syapm.2011.08.007

Hanshew, A. S., McDonald, B. R., Díaz Díaz, C., Djiéto-Lordon, C., Blatrix, R., and Currie, C. R. (2015). Characterization of Actinobacteria associated with three ant-plant mutualisms. Microb. Ecol. 69, 192-203. doi: 10.1007/s00248014-0469-3

Hanson, P. E., and Gauld, I. D. (1995). The Hymenoptera of Costa Rica. Oxford: Oxford University Press. doi: 10.1002/mmnd.19970440203

Hanson, P. E., and Nishida, K. (2016). Insects and Other Arthropods of Tropical America. Ithaca, NY: Cornell University Press.

Hatano, K., Nishii, T., and Kasai, H. (2003). Taxonomic re-evaluation of whorl-forming Streptomyces (formerly Streptoverticillium) species by using phenotypes, DNA-DNA hybridization and sequences of gyrB, and proposal of Streptomyces luteireticuli (ex Katoh and Arai 1957) corrig., sp. nov., nom. rev. Int. J. Syst. Evol. Microbiol. 53, 1519-1529. doi: 10.1099/ijs.0.02238-0

Hölldobler, B., and Wilson, E. O. (2009). The Superorganism: The Beauty, Elegance, and Strangeness of Insect Societies. New York City, NY: W.W. Norton \& Company.

Hong, S.-H., Bunge, J., Jeon, S.-O., and Epstein, S. S. (2006). Predicting microbial species richness. Proc. Natl. Acad. Sci. U.S.A. 103, 117-122. doi: 10.1073/pnas. 0507245102

Hulcr, J., Adams, A. S., Raffa, K., Hofstetter, R. W., Klepzig, K. D., and Currie, C. R. (2011). Presence and diversity of Streptomyces in Dendroctonus and sympatric bark beetle galleries across North America. Microb. Ecol. 61, 759-768. doi: 10.1007/s00248-010-9797-0

Kaltenpoth, M. (2009). Actinobacteria as mutualists: general healthcare for insects? Trends Microbiol. 17, 529-535. doi: 10.1016/j.tim.2009.09.006

Kaltenpoth, M., and Engl, T. (2013). Defensive microbial symbionts in Hymenoptera. Funct. Ecol. 28, 315-327. doi: 10.1111/1365-2435.12089

Kaltenpoth, M., Göttler, W., Herzner, G., and Strohm, E. (2005). Symbiotic bacteria protect wasp larvae from fungal infestation. Curr. Biol. 15, 475-479. doi: $10.1016 /$ j.cub.2004.12.084

Kaltenpoth, M., Roeser-Mueller, K., Koehler, S., Peterson, A., Nechitaylo, T. Y., Stubblefield, J. W., et al. (2014). Partner choice and fidelity stabilize coevolution in a Cretaceous-age defensive symbiosis. Proc. Natl. Acad. Sci. U.S.A. 111, 6359-6364. doi: 10.1073/pnas.1400457111

Kaltenpoth, M., Schmitt, T., Polidori, C., Koedam, D., and Strohm, E. (2010). Symbiotic streptomycetes in antennal glands of the South American digger wasp genus Trachypus (Hymenoptera, Crabronidae). Physiol. Entomol. 35, 196-200. doi: 10.1111/j.1365-3032.2010.00729.x

Kaltenpoth, M., Yildirim, E., Herzner, G., and Strohm, E. (2012). Refining the roots of the beewolf-Streptomyces symbiosis: antennal symbionts in the rare genus Philanthinus. Appl. Environ. Microbiol. 78, 822-827. doi: 10.1128/AEM. 06809-11

Karnovsky, M. J. (1965). A formaldehyde-glutaraldehyde fixative of high osmolality for use in electron-microscopy. J. Cell Biol. 27, 137-138.

Kim, K. W. (2008). Vapor fixation of intractable fungal cells for simple and versatile scanning electron microscopy. J. Phytopathol. 156, 125-128. doi: 10.1111/j. 1439-0434.2007.01331.x
Kroiss, J., Kaltenpoth, M., Schneider, B., Schwinger, M.-G., Hertweck, C., Maddula, R. K., et al. (2010). Symbiotic streptomycetes provide antibiotic combination prophylaxis for wasp offspring. Nat. Chem. Biol. 6, 261-263. doi: 10.1038/ nchembio. 331

Lacey, L. A. (ed.). (2012). Manual of Techniques in Invertebrate Pathology, 2nd Edn. Oxford: Academic Press.

Lane, D. (1991). "16S/23S rRNA sequencing," in Nucleic Acid Techniques in Bacterial Systematics, eds E. Stackebrandt and M. Goodfellow (Chichester: John Wiley \& Sons), 115-147.

Madden, A. A., Grassetti, A., Soriano, J. N., and Starks, P. T. (2013). Actinomycetes with antimicrobial activity isolated from paper wasp (Hymenoptera: Vespidae: Polistinae) Nests. Environ. Entomol. 42, 703-710. doi: 10.1603/EN12159

Marsh, S. E., Poulsen, M., Gorosito, N. B., Pinto-Tomás, A., Masiulionis, V. E., and Currie, C. R. (2013). Association between Pseudonocardia symbionts and Atta leaf-cutting ants suggested by improved isolation methods. Int. Microbiol. 16, 17-25. doi: 10.2436/20.1501.01.176

Mayfield, C. I., Williams, S. T., Ruddick, S. M., and Hatfield, H. L. (1972). Studies on the ecology of actinomycetes in soil IV. Observations on the form and growth of streptomycetes in soil. Soil Biol. Biochem. 4, 79-91. doi: 10.1016/0038-0717(72) 90045-4

Miller, M. A., Pfeiffer, W., and Schwartz, T. (2010). "Creating the CIPRES Science Gateway for inference of large phylogenetic trees," in Proceedings of the 2010 Gateway Computing Environments Workshop (GCE) (IEEE), New Orleans, LA, 1-8. doi: 10.1109/GCE.2010.5676129

Oh, D.-C., Poulsen, M., Currie, C. R., and Clardy, J. (2009). Dentigerumycin: a bacterial mediator of an ant-fungus symbiosis. Nat. Chem. Biol. 5, 391-393. doi: $10.1038 /$ nchembio. 159

Oi, D. H., and Pereira, R. M. (1993). Ant behavior and microbial pathogens (Hymenoptera: Formicidae). Florida Entomol. 76, 63-74. doi: 10.2307/3496014

Penn, O., Privman, E., Ashkenazy, H., Landan, G., Graur, D., and Pupko, T. (2010). GUIDANCE: a web server for assessing alignment confidence scores. Nucleic Acids Res. 38, W23-W28. doi: 10.1093/nar/gkq443

Pontoppidan, M.-B., Himaman, W., Hywel-Jones, N. L., Boomsma, J. J., and Hughes, D. P. (2009). Graveyards on the move: the spatio-temporal distribution of dead Ophiocordyceps-infected ants. PLOS ONE 4:e4835. doi: 10.1371/ journal.pone.0004835

Poulsen, M., Oh, D.-C., Clardy, J., and Currie, C. R. (2011). Chemical analyses of wasp-associated Streptomyces bacteria reveal a prolific potential for natural products discovery. PLOS ONE 6:e16763. doi: 10.1371/journal.pone. 0016763

Promnuan, Y., Kudo, T., and Chantawannakul, P. (2009). Actinomycetes isolated from beehives in Thailand. World J. Microbiol. Biotechnol. 25, 1685-1689. doi: 10.1007/s11274-009-0051-1

Rehner, S. A., and Buckley, E. (2005). A Beauveria phylogeny inferred from nuclear ITS and EF1- $\alpha$ sequences: evidence for cryptic diversification and links to Cordyceps teleomorphs. Mycologia 97, 84-98. doi: 10.3852/mycologia. 97.1.84

Reyes, R. D. H., and Cafaro, M. J. (2014). Paratrechina longicornis ants in a tropical dry forest harbor specific Actinobacteria diversity. J. Basic Microbiol. 55, 11-21. doi: $10.1002 / j o b m .201300785$

Ronquist, F., and Huelsenbeck, J. P. (2003). MrBayes 3: Bayesian phylogenetic inference under mixed models. Bioinformatics 19, 1572-1574. doi: 10.1093/ bioinformatics/btg 180

Samson, R. A., Evans, H. C., and Latge, J.-P. (2013). Atlas of Entomopathogenic Fungi. Berlin: Springer Science \& Business Media.

Sanjuan, T. I., Franco-Molano, A. E., Kepler, R. M., Spatafora, J. W., Tabima, J., Vasco-Palacios, A. M., et al. (2015). Five new species of entomopathogenic fungi from the Amazon and evolution of neotropical Ophiocordyceps. Fungal Biol. 119, 901-916. doi: 10.1016/j.funbio.2015.06.010

Schloss, P. D., and Handelsman, J. (2004). Status of the microbial census. Microbiol. Mol. Biol. 68, 689-691. doi: 10.1128/MMBR.68.4.686-691.2004

Schloss, P. D., Westcott, S. L., Ryabin, T., Hall, J. R., Hartmann, M., Hollister, E. B., et al. (2009). Introducing mothur: open-source, platform-independent, community-supported software for describing and comparing microbial communities. Appl. Environ. Microbiol. 75, 7537-7541. doi: 10.1128/AEM. 01541-09

Simmons, D. R., Kepler, R. M., Rehner, S. A., and Groden, E. (2015). Phylogeny of Hirsutella species (Ophiocordycipitaceae) from the UsA: remedying the paucity 
of Hirsutella sequence data. IMA Fungus 6, 345-356. doi: 10.5598/imafungus. 2015.06.02.06

Sit, C. S., Ruzzini, A. C., Van Arnam, E. B., Ramadhar, T. R., Currie, C. R., and Clardy, J. (2015). Variable genetic architectures produce virtually identical molecules in bacterial symbionts of fungus-growing ants. Proc. Natl. Acad. Sci. U.S.A. 112, 13150-13154. doi: 10.1073/pnas.1515348112

Suay, I., Arenal, F., Asensio, F. J., Basilio, A., Cabello, M. A., Díez, M. T., et al. (2000). Screening of basidiomycetes for antimicrobial activities. Antonie Van Leeuwenhoek 78, 129-140. doi: 10.1023/A:1026552024021

Sung, G.-H., Hywel-Jones, N. L., Sung, J.-M., Luangsa-Ard, J. J., Shrestha, B., and Spatafora, J. W. (2007). Phylogenetic classification of Cordyceps and the clavicipitaceous fungi. Stud. Mycol. 57, 5-59. doi: 10.3114/sim.2007.57.01

Tamura, K., Stecher, G., Peterson, D., Filipski, A., and Kumar, S. (2013). MEGA6: molecular evolutionary genetics analysis version 6.0. Mol. Biol. Evol. 30, 2725-2729. doi: 10.1093/molbev/mst197

van der Meij, A., Worsley, S. F., Hutchings, M. I., and van Wezel, G. P. (2017). Chemical ecology of antibiotic production by actinomycetes. FEMS Microbiol. Rev. 41, 392-416. doi: 10.1093/femsre/fux005

Větrovský, T., Steffen, K. T., Baldrian, P., Rouard, N., and Martin-Laurent, F. (2014). Potential of cometabolic transformation of polysaccharides and lignin in lignocellulose by soil Actinobacteria. PLOS ONE 9:e89108. doi: 10.1371/journal. pone.0089108

Ward, P. S. (2014). The phylogeny and evolution of ants. Annu. Rev. Ecol. Evol. Syst. 45, 23-43. doi: 10.1146/annurev-ecolsys-120213-091824
White, T., Bruns, T., Lee, S., and Taylor, J. (1990). "Amplification and direct sequencing of fungal ribosomal RNA genes for phylogenetics," in PCR Protocols: A Guide to Methods and Applications, eds N. Innis, D. Gelfand, J. Sninsky, and T. White (New York, NY: Academic Press), 315-322.

Wilson, E. O. (1971). The Insect Societies. Cambridge, MA: Belknap Press of Harvard University Press.

Wilson-Rich, N., Spivak, M., Fefferman, N. H., and Starks, P. T. (2009). Genetic, individual, and group facilitation of disease resistance in insect societies. Annu. Rev. Entomol. 54, 405-423. doi: 10.1146/annurev.ento.53.103106.093301

Zhang, Y. J., Zhang, S., Liu, X. Z., Wen, H. A., and Wang, M. (2010). A simple method of genomic DNA extraction suitable for analysis of bulk fungal strains. Lett. Appl. Microbiol. 51, 114-118. doi: 10.1111/j.1472-765X.2010.02867.x

Conflict of Interest Statement: The authors declare that the research was conducted in the absence of any commercial or financial relationships that could be construed as a potential conflict of interest.

Copyright (c) 2017 Matarrita-Carranza, Moreira-Soto, Murillo-Cruz, Mora, Currie and Pinto-Tomas. This is an open-access article distributed under the terms of the Creative Commons Attribution License (CC BY). The use, distribution or reproduction in other forums is permitted, provided the original author(s) or licensor are credited and that the original publication in this journal is cited, in accordance with accepted academic practice. No use, distribution or reproduction is permitted which does not comply with these terms. 